\title{
Combinations of Nanomaterials and Deep Eutectic Solvents as Innovative Materials in Food Analysis
}

\author{
Álvaro Santana-Mayor ${ }^{1}{ }^{\mathbb{D}}$, Ruth Rodríguez-Ramos ${ }^{1}$, Bárbara Socas-Rodríguez ${ }^{1} \mathbb{D}$, María del Mar Afonso $^{2}$ and \\ José A. Palenzuela $2, *$ (D)
}

1 Unidad Departamental de Química Analítica, Departamento de Química, Facultad de Ciencias, Universidad de La Laguna (ULL), Avenida Astrofísico Francisco Sánchez s/n, 38206 San Cristóbal de La Laguna, Santa Cruz de Tenerife, Spain; asantanm@ull.edu.es (Á.S.-M.); rrodrira@ull.edu.es (R.R.-R.); bsocasro@ull.edu.es (B.S.-R.)

2 Departamento de Química Orgánica, Instituto Universitario de Bio-Orgánica Antonio González, Universidad de La Laguna (ULL), P.O. Box 456, 38200 San Cristóbal de La Laguna, Santa Cruz de Tenerife, Spain; mmafonso@ull.edu.es

* Correspondence: jpalenz@ull.edu.es; Tel.: +34-92-231-8443

check for updates

Citation: Santana-Mayor, Á.; Rodríguez-Ramos, R.;

Socas-Rodríguez, B.; Afonso, M.d.M.;

Palenzuela, J.A. Combinations of

Nanomaterials and Deep Eutectic Solvents as Innovative Materials in Food Analysis. Processes 2021, 9, 2131 https://doi.org/10.3390/pr9122131

Academic Editor: Fabiano André Narciso Fernandes

Received: 2 November 2021

Accepted: 23 November 2021

Published: 25 November 2021

Publisher's Note: MDPI stays neutral with regard to jurisdictional claims in published maps and institutional affiliations.

Copyright: (c) 2021 by the authors. Licensee MDPI, Basel, Switzerland. This article is an open access article distributed under the terms and conditions of the Creative Commons Attribution (CC BY) license (https:/ / creativecommons.org/licenses/by/ $4.0 /)$.

\begin{abstract}
The application of nanotechnology has been an important tool in the development of sustainable analytical procedures which have been developed in agreement with the principles of sustainability and green chemistry. In this sense, such materials have been widely applied in the area of food analysis providing important improvements in terms of specificity, efficiency, and simplicity. Besides, in recent years, the discovery of other innovative materials developed in the framework of green chemistry, such as deep eutectic solvents (DESs), has gained special attention from the scientific community for whom the design and successful application of sustainable strategies is a huge challenge. In this sense, the recent combination of nanomaterials and DESs have resulted in the performance of suitable approaches in the area of food sciences bringing about interesting alternatives in food analysis. The aim of this review article is to revise the application of nanomaterials combined with DESs in food analysis, paying special attention to the synthesis and characterization steps, as well as to the performance of the most recent approaches developed in the field for the analysis of food commodities.
\end{abstract}

Keywords: green solvents; magnetic-nanoparticles; food analysis; molecularly imprinted polymer; graphene; nanotubes

\section{Introduction}

The accomplishment of the objectives established by the 2030 Agenda for Sustainable Development has become an outstanding issue. There is a great endeavor around the world to modify lifestyles and work methodologies in order to accomplish such aims. Such guidelines encourage each person and institution to work hard with the aim of improving the quality of life of each citizen and, at the same time, preserving all the elements that constitute our world. Reaching each of the aspects included in this agenda involves a huge effort that should be carried out to guarantee a better and more sustainable planet [1].

One of the areas that have a higher influence on the development of society is the agro-food sector. In Europe, the agro-food industry has a turnover of 1.2 trillion euros with 4.8 million employees [2] and the increase of the global population involves an expansion of this industry. In fact, The Food and Agriculture Organization of the United Nations (FAO) forecasts that the feeding of the population in 2050 (10 billion people) will require a radical modification of how food is produced, processed, traded, and consumed [3]. All these aspects have raised the concern of consumers for modern food risk. Besides, the diverse food safety incidents that occurred in the last years together with the increased information received from different experts about the negative effect that several additives 
and preservatives have on human health have brought about the skepticism of the population about the quality of food and the concern of global institutions to guarantee the principles of safety and sustainability in the food industry [4].

Within this framework, the adaptation of the 12 Principles of Green Chemistry to analytical procedures carried out in food sciences has gained great relevance, not only to avoid fraud in commercialization or to assure the quality and safety of food commodities but also to showcase the importance of the concept of circular economy on the development of a more sustainable agro-food industry. This approach, which is based on the adaptation of green chemistry to green analytical chemistry applied in the area of food sciences, attempts to reach the 12 principles by the application of different strategies such as simplification of the procedures, in-situ analysis, removal or reduction of the use of toxic solvents, miniaturization or application of novel and more sustainable materials, among others [5].

The assistance of material science in analytical chemistry has played a relevant role in recent years. The application of novel and functional materials provides numerous advantages, not only because of the removal of other more toxic and less biodegradable materials but also because those make it possible to minimize the consumption of hazardous solvents, simplify the procedures, and miniaturize them decreasing the economical and energetic cost. Among the different solid materials developed, including polymers, molecularly imprinted polymers (MIPs), natural sorbents, etc., the development of nanomaterials has clearly been underscored [6,7].

Nanomaterials are characterized by presenting a small size, in the range 1-100 nm, which gives these materials a great surface area as well as other particular and unique characteristics that make them ideal to be used as sorbents in analytical chemistry, and particularly in food analysis, in which the great complexity of the evaluated matrices make necessary the utilization of very effective elements. Besides, such materials can be used in low amounts due to the great number of active points present on their surface which favors the reduction of organic solvents as well as the simplification of the procedure in agreement with the aim of sustainability. Among the nanomaterials applied in the area of food analysis, carbon-based nanotubes, metal-organic frameworks (MOFs), and nanoparticles (NPs), pointing out magnetic-NPs (m-NPs), have been the most widely applied [8].

Apart from that, the development of liquid novel materials has also been achieved. The search for less toxic solvents that can be proposed as solid alternatives to the widely used conventional organic solvents constitutes a big challenge for the scientific community. For years, the use of the well-known Generally Recognized as Safe (GRAS) solvents, which are considered reliable to be used in the food industry (i.e., water, supercritical $\mathrm{CO}_{2}$, ethanol, etc.), has been thoroughly studied with very good results $[9,10]$. In the same way, the appearance of ionic liquids (ILs) as environmentally friendly solvents also constituted an important advance in the field since they present interesting physicochemical properties such as adequate viscosity, thermal stability, conductivity, and solubility which, in addition, can be customized by the combination of a great variety of organic and inorganic anions. However, such materials have been shown to be less green than was thought at the beginning with a certain toxicity, poor biodegradability, and high cost [11].

As a new alternative in the last 20 years, the development of a new generation of green solvents, the so-called deep eutectic solvents (DESs), has surged with a meteoric rise in the number of applications in numerous fields, including food analysis. These materials constituted for at least one hydrogen bond donor (HBD) and one hydrogen bond acceptor (HBA) in a specific molar ratio, come up with a eutectic mixture whose melting point is considerably lower than the initial components and even lower than the theoretical eutectic point. Their raising interest is related to their easy and inexpensive synthesis and the large variety and availability of raw materials, as well as their low toxicity, biodegradability, and biocompatibility. This is especially remarkable for the named natural-DESs (NADESs), those exclusively constituted of secondary metabolites and other compounds usually 
present in cells. Besides, their particular physicochemical characteristics such as low vapor pressure, high thermal stability, and the possibility of tailoring such characteristics depending on the type of DES used have enhanced their applications [12].

DESs have been widely applied as extractions solvents, in the preparation of sensors, as modifiers in stationary and mobile phases in chromatography in food analysis, but their application as modifiers or as part of specific sorbents together with nanomaterials have also been reported. These combinations are easily prepared and provide a remarkable improvement on the extraction procedures thanks to the synergy of the different components, not only to enhance the extraction efficiency or selectivity but also to favor the extraction performance and simplify the procedure. In this sense, different types of DESs have been combined with m-NPs alone or in presence of other novel materials such as MIPs, with carbon-based nanomaterials or MOFs, principally, and their roles have been varied depending on the application and the approach applied.

The aim of this review article is to carry out a thorough revision of the application of the nanomaterials and DESs combinations in food analysis including food safety and quality studies, as well as bioactivity evaluations. In this sense, the most common synthetic strategies as well as the relevance of materials characterization and customized design will be described and critically discussed. In addition, the most applied approaches and current trends in the area will be pointed out in order to provide a general overview of this hot topic.

\section{Synthesis and Characterization of Nanomaterials and DESs Combinations}

\subsection{Synthesis}

\subsubsection{Magnetic Nanoparticles with DESs}

The synthesis of the magnetic-DESs (MDESs) generally follows a simple two-steps procedure. First, the m-NPs and the DES are independently prepared, and then both are mixed and stirred or sonicated at a certain temperature until the final compound is obtained. The m-NPs are usually prepared by the co-precipitation method. In this method, an aqueous mixture of Fe (III) and Fe (II) salts in a 2:1 molar ratio is used and a base such as $\mathrm{NH}_{4} \mathrm{OH}$ or $\mathrm{NaOH}$ is then added under stirring. The rate of addition, temperature, and stirring determine the size of the $\mathrm{Fe}_{3} \mathrm{O}_{4}$ NPs. The m-NPs can be used as prepared or can be modified before mixing them with the DES. Those modifications can range from coating with oleic acid [13] or polydopamine [14] to the formation of a core-shell structure with $\mathrm{SiO}_{2}$ using tetraethoxysilane (TEOS) $[15,16]$. The DES can be binary (BDES) or ternary (TDES) and is prepared by mixing the components with stirring at a certain temperature until a homogeneous liquid is formed. The ratio of the components of the DES is of importance in its stability and physical properties.

A few examples reported in the literature use other different procedures for the preparation of MDESs. In one case [17], the MDES was prepared directly by adding $\mathrm{FeCl}_{3}$ to choline chloride $(\mathrm{ChCl})$ and $\mathrm{p}$-cresol under stirring at $80{ }^{\circ} \mathrm{C}$. This yields magnetic $\left[\mathrm{ChCl} / \mathrm{p}\right.$-cresol] $\left[\mathrm{FeCl}_{4}\right]$. In another example [18], the preparation of the MDES took place after the extraction of the analytes by the DES, composed of ethylene glycol and tetrabutylammonium chloride (TBAC), by adding $\mathrm{FeCl}_{3}$ to form m-NPs which facilitates the separation of the extracted analytes.

BDESs and TDESs have been used in the preparation of magnetic-MIPs (MMIPs), and different approaches have been undertaken to prepare the target compounds. In some cases, a mixture of the DES and boron nitrile was prepared as a functional monomer, and the template, the cross-linker, and the m-NPs were introduced later in the polymerization step [19]. A similar procedure, using $\mathrm{MoS}_{2}$ as a base was reported. DES, a cross-linker, an initiator, m-NPs, and the $\mathrm{MoS}_{2}$ sheets were mixed and sonicated. Then, the template and N, N-dimethyl aniline were added and allowed to react to form the polymer [20]. In other cases, the synthesis was started by mixing and heating the m-NPs and the DES. Then, methacrylic acid (MAA), and the templates were added and sonicated. Lastly, the crosslinker and the initiator were added and heated to form the MMIP-DES compound [21]. In 
yet another case, the templates and MAA were reacted for pre-polymerization. Then, the m-NPs modified with $\mathrm{SiO}_{2}$, the cross-linker, and the initiator were introduced, and the mixture was heated for the polymerization step [22]. Similarly, Tan et al. [23] designed an MMIP based on a TDES of ChCl:caffeic acid:formic acid (1:6:3) and the protein zein. In a first step, the TDES and the template were mixed for pre-polymerization. Then, the m-NPs and zein, as the cross-linker, were added, sonicated, and finally shaken. Lastly, the solid was washed and distilled water was added for the self-polymerization ability of zein in water. In an interesting work [24], the template was used as part of a TDES to overcome solubility problems. However, in this case, no m-NPs were used in the synthesis of the MIP.

\subsubsection{Combination of MOFs and Carbon-Based Nanomaterials with DESs}

A few examples of the use of MOF/DES combinations for the analysis of food have been published. In one case [25], the MOF and the DES were prepared separately and then mixed with the addition of a template and the reagents needed to polymerize the mixture and to prepare a MIP. Using the polymerization reaction, monolithic and hollow fibers were prepared and used for the solid-phase microextraction (SPME) of phthalate esters from yogurt, water, and edible oil.

Magnetic MOF/DES sorbents have been prepared by the synthesis of the m-NPs by the solvothermal method, preparing the MOF using those m-NPs, and then linking the resulting MOF to a DES using N-(3-dimethylaminopropyl)- $\mathrm{N}^{\prime}$-ethylcarbodiimide hydrochloride/N-hydroxysuccinimide chemistry [26,27]. These materials have been used for the microextraction of RNA from yeast or pharmaceuticals.

Another synthesis of magnetic MOF and polymeric-DES (poly-DES) was reported [28]. The synthetic procedure is similar to the previous example, but the DES was used as a monomer to prepare the final compound containing poly-DES, m-NP@MOF@poly-DES, which was used for the extraction of cationic dyes.

Carbon-based nanomaterials modified by DESs have been used for the extraction of different compounds in food. The carbon materials used so far, have been graphene [29], graphene oxide (GO) (doped with nitrogen or boron [30] or decorated with m-NPs [31,32]), and multi-walled carbon nanotubes (MWCNTs) linked to m-NPs [33,34], or pristine [35]. In most cases, the carbon-based nanomaterial and the DES were mixed and sonicated to obtain the desired sorbent. However, in one case, MWCNTs and DES were mixed and subjected to ball-milling to obtain the desired compound [35].

Recently, the hydrothermal synthesis of DES-based N,Cl-doped carbon dots was carried out [36]. For this purpose, glycine (as the carbon source) was dissolved into the $\mathrm{ChCl}$ :urea DES and heated in a Teflon-coated autoclave. Finally, the carbon dots formed were purified with an external $1000 \mathrm{Da}$ dialysis membrane.

\subsection{Characterization}

\subsubsection{Magnetic Nanoparticles with DESs}

The characterization of the different families of compounds containing DESs and magnetic nanomaterials is carried out using the usual techniques associated with solid compounds. In several papers, no mention is made of the characterization of the final compounds $[18,37]$. In some others, the precursors are characterized and then the final compound is used without further study of the structure [13]. Others, however, follow the different stages of the synthesis using an appropriate technique. Fourier transform infrared spectroscopy (FTIR) is used to follow the changes in the stretching of the $\mathrm{OH}$ groups from the ethylene glycol-containing DES when mixed with the silicon-covered m-NPs [16]. For the same purpose, scanning electron microscopy (SEM) has been used to observe the variation in size of the m-NP when covered with the DES [15]. The most exhaustive study of the MDES has been performed using FTIR, SEM, X-ray diffraction (XRD) analysis, and vibrating sample magnetometer (VSM), characterizing all aspects of the compounds, from the internal structure to magnetization characteristics [14]. 
All papers describing MIPs based on or modified with DES include the characterization of the final compounds. At least FTIR and SEM are used to follow the different stages of the synthesis [21-23]. Other authors use a more extensive array of methods for structural characterization. Apart from FTIR and SEM, transmission electron microscopy (TEM), thermogravimetric analysis (TGA), Brunauer-Emmett-Teller (BET) surface analysis, XRD, X-ray photoelectron spectroscopy (XPS), VSM, or elemental analysis are used to confirm the structure of the imprinted polymer $[19,20,23]$.

\subsubsection{Combination of MOFs and Carbon-Based Nanomaterials with DESs}

For the characterization of DES-containing MOF, at least FTIR, SEM, XRD, and TGA are reported [25-28]. Those techniques are used to compare the results of the different synthetic stages for the preparation of the MOF. Other techniques used are TEM, VSM when the compound is magnetic [26-28], and dynamic light scattering to measure the size of the particles in each stage [26,27].

The different carbon-based substrates used for the carbon-based nanomaterial-DES combinations have been characterized by the techniques used for the pristine materials, FTIR [29-36] and SEM [29-35] being the most used ones. Other techniques used are TEM $[29,35,36]$ BET surface analysis $>[30,32]$, XRD [30,32,35], ultraviolet (UV) [35,36], atomic force microscopy [30], TGA [35], XPS [36], and, when m-NPs are used, VSM [33, 34] or alternating gradient force magnetometry [32]. The comparison between the final compound and the previous step in the synthesis is commonly used to establish the nature of the nanomaterials.

\section{Applications of Nanomaterials and DESs Combinations in Food Analysis}

\subsection{Combination of Magnetic Nanoparticles with DESs}

Among the different DESs-based nanomaterials used for food analysis, the combination of these solvents with pristine or functionalized m-NPs $[13-16,18,37,38]$ and MMIPs [19-23] stand out (see Table 1). In this regard, they have been mainly applied for the evaluation of tea samples [16,21,22,37], although other matrices such as edible oils [38], cereals [18], meat [15], milk [13,20], fruits [16], vegetables [16], beverages [16,23], drinking water [14], and edible plants [19], among others, have also been analyzed. Concerning the compounds studied, a wide variety of both organic contaminants (perfluoroalkyl substances [38], herbicides [14,18], polycyclic aromatic hydrocarbons (PAHs) [15], and pharmaceuticals [13]), biomolecules (flavonols [16,19], proteins [20], catechins [22], and alkaloids [21], etc.), aspartame [23], and metals [37] have been determined.

With the purpose of achieving the best extraction performance, several DESs components have been evaluated giving rise to those formed by compounds of natural and non-natural occurrence. In this way, $\mathrm{ChCl}[19-23,37,38]$, as the most used HBA, and others such as TBAC [18], tetramethyl- (TMAC) [16], and dioctadecyldimethylammonium chloride [14], and phosphocholine chloride [15], all of them with a hydrophilic profile, and menthol [13] as a hydrophobic component, have been employed. Moreover, different alcohols, including ethylene glycol [16,18,19], phenol [37], and derivatives [14], menthol [15], or glycerol [22], formic acid [23] or unsaturated carboxylic acids (acrylic [20] and caffeic [19,23] acids), and medium-chain fatty acids (octanoic [13] and decanoic [15] acids), and amides such as urea [21] or 1-(o-tolyl)biguanide [38], have been utilized as HBDs. The ability of some of these compounds, such as menthol, to act like both HBA and HBD is remarkable. In terms of miscibility in water, most of the DESs evaluated are made up of water-soluble components [16,18-23,37]. However, applications of hydrophobic DESs (HDESs) [13] or pseudo-HDESs $[14,15,38]$ can also be found. 
Table 1. Some examples of the application of innovative combinations of magnetic nanoparticles with DESs in food analysis.

\begin{tabular}{|c|c|c|c|c|c|c|c|}
\hline $\begin{array}{l}\text { Sample } \\
\text { (Amount) }\end{array}$ & Analytes & $\begin{array}{c}\text { Sorbent } \\
\text { (DES Molar Ratio; Amount) }\end{array}$ & $\begin{array}{l}\text { Extraction } \\
\text { Procedure }\end{array}$ & $\begin{array}{l}\text { Analytical } \\
\text { Technique }\end{array}$ & $\begin{array}{l}\text { Recovery \% } \\
\text { LOD }\end{array}$ & Comments & Reference \\
\hline \multicolumn{8}{|c|}{ DES-based $m$-NPs } \\
\hline $\begin{array}{l}\text { Edible oil } \\
\quad(7 \mathrm{~g})\end{array}$ & $\begin{array}{l}5 \text { Perfluoroalkyl } \\
\text { substances }\end{array}$ & $\begin{array}{c}\text { ChCl:1-(o-tolyl)biguanide@ } \mathrm{Fe}_{3} \mathrm{O}_{4} \\
(1: 1 ; 20 \mu \mathrm{L})\end{array}$ & m-LPME & UHPLC-Q-ToF-MS & $\begin{array}{c}90-109 \\
0.3-1.6 \mathrm{ng} / \mathrm{kg}\end{array}$ & $\begin{array}{c}\text {-Other molar ratios (1:4, 1:2, 3:2, and 2:1) were also } \\
\text { studied. } \\
\text {-Methanol was used as back-extraction solvent } \\
\text { (50 } \mu \mathrm{L}) \text {. } \\
\text {-The method was applied to the analysis of olive, } \\
\text { sesame, sunflower seed, corn, camellia seed, soybean, } \\
\text { blended, and vegetable oils. }\end{array}$ & [38] \\
\hline $\begin{array}{l}\text { Rice } \\
(1 \mathrm{~g})\end{array}$ & $\begin{array}{l}5 \text { Triazine } \\
\text { herbicides }\end{array}$ & $\begin{array}{c}\text { TBAC:ethylene glycol@ } \mathrm{FeCl}_{4} \\
(1: 2 ;-)\end{array}$ & $\mathrm{m}-\mu-\mathrm{dSPE}$ & HPLC-UV/Visible & $\begin{array}{c}85-117 \\
1.49-3.10 \mu \mathrm{g} / \mathrm{kg}\end{array}$ & $\begin{array}{c}\text {-The magnetic DES was formed in-situ ( } 250 \mu \mathrm{L} \text { of } \\
\left.\text { DES and } 40 \mathrm{mg} \text { of } \mathrm{FeCl}_{3}\right) \text {. } \\
\text {-Other molar ratios }(1: 1,1: 3 \text {, and } 1: 4) \text { were also } \\
\text { studied. } \\
\text {-Diethyl ether was used as back-extraction solvent } \\
\text { ( } 5 \mathrm{~mL}) \text {. } \\
\text {-The accuracy of the method was also evaluated in a } \\
\text { maize sample (78-105\%). }\end{array}$ & [18] \\
\hline $\begin{array}{l}\text { Grilled meat } \\
\quad(10 \mathrm{~g})\end{array}$ & 16 PAHs & $\begin{array}{c}\text { Phosphocholine } \\
\text { chloride:menthol:decanoic } \\
\text { acid-TEOS@ } \mathrm{Fe}_{3} \mathrm{O}_{4} \\
(1: 1: 1 ; 90 \mu \mathrm{L})\end{array}$ & UA-m-LPME & GC-Q-MS & $\begin{array}{c}73-92 \\
29-82 \mathrm{ng} / \mathrm{kg}\end{array}$ & $\begin{array}{l}\text {-The TDES was used as support. } \\
\text {-Hexanoic and heptanoic acids were also studied as } \\
\text { DES components. } \\
\text {-n-hexane was used as back-extraction solvent }(10 \mu \mathrm{L}) \text {. } \\
\text {-The method was applied to the analysis of kebabs } \\
\text { and hamburgers. }\end{array}$ & [15] \\
\hline $\begin{array}{l}\text { Eucalyptus } \\
\text { and rosemary } \\
\text { tea } \\
(2 \mathrm{~g})\end{array}$ & $\mathrm{Cd}$ & $\begin{array}{c}\text { ChCl:phenol@ } \mathrm{Fe}_{3} \mathrm{O}_{4} \\
(1: 3 ; 50 \mu \mathrm{L})\end{array}$ & $\mathrm{m}-\mu-\mathrm{dSPE}$ & $\begin{array}{l}\text { Slotted quartz } \\
\text { tube-FAAS }\end{array}$ & $\begin{array}{c}91-110 \\
0.25 \mu \mathrm{g} / \mathrm{L}\end{array}$ & $\begin{array}{c}\text {-Other molar ratios }(1: 1,1: 2 \text {, and 1:4) were } \\
\text { also studied. } \\
-\mathrm{HNO}_{3}(5 \mathrm{M}) \text { was used as back-extraction solvent } \\
\quad(150 \mu \mathrm{L}) \text {. } \\
\text {-The accuracy of the method was confirmed by } \\
\text { comparing the developed method with ICP-OES } \\
\text { determination. }\end{array}$ & [37] \\
\hline $\begin{array}{l}\text { Milk } \\
(6 \mathrm{~mL})\end{array}$ & Doxycycline & $\begin{array}{c}\text { DL-menthol:octanoic acid@oleic } \\
\text { acid-Fe } \mathrm{O}_{3} \\
(1: 1 ; 150 \mu \mathrm{L})\end{array}$ & VA-m-LPME & HPLC-UV & $\begin{array}{c}87-94 \\
3.6 \mu \mathrm{g} / \mathrm{L}\end{array}$ & $\begin{array}{l}\text {-Ferrofluid contained } 50 \mathrm{mg} \text { of m-NPs per millilitre } \\
\text { of DES. } \\
\text {-Methanol was used as back-extraction solvent } \\
\quad(20 \mu \mathrm{L}) \text {. } \\
\text {-The method was also applied to the analysis of urine } \\
\text { and blood plasma. }\end{array}$ & [13] \\
\hline
\end{tabular}


Table 1. Cont.

\begin{tabular}{|c|c|c|c|c|c|c|c|}
\hline $\begin{array}{l}\text { Sample } \\
\text { (Amount) }\end{array}$ & Analytes & $\begin{array}{c}\text { Sorbent } \\
\text { (DES Molar Ratio; Amount) }\end{array}$ & $\begin{array}{l}\text { Extraction } \\
\text { Procedure }\end{array}$ & $\begin{array}{l}\text { Analytical } \\
\text { Technique }\end{array}$ & $\begin{array}{l}\text { Recovery \% } \\
\text { LOD }\end{array}$ & Comments & Reference \\
\hline \multicolumn{8}{|c|}{ DES-based m-NPs } \\
\hline $\begin{array}{l}\text { Apple and } \\
\text { grape juices, } \\
\text { green tea, } \\
\text { and onion } \\
\quad(-)\end{array}$ & $\begin{array}{c}\text { Morin } \\
\text { (Flavonol) }\end{array}$ & $\begin{array}{c}\text { TMAC:ethylene } \\
\text { glycol@SiO } \mathrm{Si}_{2} @ \mathrm{Fe}_{3} \mathrm{O}_{4} \\
(1: 3 ;-)\end{array}$ & $\mathrm{m}-\mu-\mathrm{dSPE}$ & HPLC-UV & $\begin{array}{c}83-99 \\
0.91 \mu \mathrm{g} / \mathrm{L}\end{array}$ & $\begin{array}{c}\text {-Ferrofluid contained } 7 \mathrm{mg} \text { of m-NPs and } 150 \mu \mathrm{L} \\
\text { of DES. } \\
\text {-Other molar ratios (1:1 to 1:5) were also studied. } \\
\text {-Ethanol was used as back-extraction solvent }(250 \mu \mathrm{L}) \text {. } \\
\text {-DES@SiO } \mathrm{DEF}_{2} @ \mathrm{O}_{4} \text { and } \mathrm{SiO}_{2} @ \mathrm{Fe}_{3} \mathrm{O}_{4} \mathrm{~m}-\mathrm{NPs} \\
\text { based-extractions were compared. }\end{array}$ & [16] \\
\hline $\begin{array}{l}\text { Drinking } \\
\text { water } \\
(100 \mathrm{~mL})\end{array}$ & $\begin{array}{l}4 \text { Sulfonylurea } \\
\text { herbicides }\end{array}$ & $\begin{array}{l}\text { Dioctadecyldimethylammonium } \\
\text { chloride:4- } \\
\text { chlorophenol@polydopamine@ } \mathrm{Fe}_{3} \mathrm{O}_{4} \\
(1: 5 ; 50 \mathrm{mg})\end{array}$ & UA-m- $\mu-d S P E$ & UHPLC-PDA & $\begin{array}{c}76-108 \\
0.0098-0.0110 \mu \mathrm{g} / \mathrm{L}\end{array}$ & $\begin{array}{c}\text {-ACN was used as back-extraction solvent }(1.5 \mathrm{~mL}) \text {. } \\
\text {-The method was applied to the analysis of } \\
\text { commercialized products, as well as } \\
\text { environmental waters. }\end{array}$ & [14] \\
\hline \multicolumn{8}{|c|}{ MIPs-DES-based m-NPs } \\
\hline $\begin{array}{l}\text { Soft drinks } \\
\qquad(-)\end{array}$ & Aspartame & $\begin{array}{c}\text { ChCl:caffeic acid:formic } \\
\text { acid@zein@ } @ \mathrm{Fe}_{3} \mathrm{O}_{4} \\
(1: 6: 3 ;-)\end{array}$ & - & $\begin{array}{l}\text { Differential pulse } \\
\text { voltammetry }\end{array}$ & $\begin{array}{c}85-107 \\
-\end{array}$ & $\begin{array}{c}\text {-DES was used as functional monomer and zeis as } \\
\text { cross-linker. } \\
\text {-Fifteen } \mu \mathrm{L}(1.5 \mathrm{mg} / \mathrm{mL}) \text { of MMIP was deposited } \\
\text { onto a magnetic glassy carbon electrode surface. } \\
\text {-Sorbent selectivity against acesulfame and } \\
\text { glycyrrhizin acid was evaluated. } \\
\text {-Adsorption capacity was } 12.86 \mathrm{mg} / \mathrm{g} \text {. }\end{array}$ & [23] \\
\hline $\begin{array}{l}\text { Ginkgo biloba } \\
\text { leaves } \\
(-)\end{array}$ & $\begin{array}{l}\text { Quercetin, } \\
\text { isorhamnetin, and } \\
\text { kaempferol }\end{array}$ & $\begin{array}{l}\text { Poly(ChCl:caffeic acid:ethylene } \\
\text { glycol)-boron nitride@ } \mathrm{Fe}_{3} \mathrm{O}_{4} \\
(5: 1: 5 ; 50 \mathrm{mg})\end{array}$ & $\mathrm{m}-\mu-\mathrm{dSPE}$ & HPLC-UV & $\begin{array}{c}94-97 \\
-\end{array}$ & $\begin{array}{l}\text {-Other molar ratios of TDESs including 1:1:1, 2:1:2, } \\
\text { 3:1:3, 8:1:8, 10:1:10, and 15:1:15 were also studied. } \\
\text {-Quercetin was used as template and TDESs as } \\
\text { functional monomers. } \\
\text {-Ethanol was used as back-extraction solvent }(10 \mathrm{~mL}) \text {. } \\
\text {-The sorbent could be used for three } \\
\text { adsorption/desorption cycles. } \\
\text {-Poly-DES-boron nitride@ @ } \mathrm{Fe}_{3} \mathrm{O}_{4} \text { and } \\
\text { poly-DES@Fe } \mathrm{O}_{4} \text { MIPs and NIPs extraction } \\
\text { performances were compared. }\end{array}$ & [19] \\
\hline
\end{tabular}


Table 1. Cont.

\begin{tabular}{|c|c|c|c|c|c|c|c|}
\hline $\begin{array}{l}\text { Sample } \\
\text { (Amount) }\end{array}$ & Analytes & $\begin{array}{c}\text { Sorbent } \\
\text { (DES Molar Ratio; Amount) }\end{array}$ & $\begin{array}{l}\text { Extraction } \\
\text { Procedure }\end{array}$ & $\begin{array}{l}\text { Analytical } \\
\text { Technique }\end{array}$ & $\begin{array}{l}\text { Recovery \% } \\
\text { LOD }\end{array}$ & Comments & Reference \\
\hline \multicolumn{8}{|c|}{ MIPs-DES-based m-NPs } \\
\hline $\begin{array}{c}\text { Milk } \\
(-)\end{array}$ & $\beta$-Lactoglobulin & $\begin{array}{l}\text { Poly(ChCl-acrylic } \\
\text { acid)@MoS } \mathrm{MFe}_{2} @ \mathrm{O}_{4} \\
(1: 2 ; 20 \mathrm{mg})\end{array}$ & $\mu$-dSPE & HPLC-UV/Visible & $0.7 \mathrm{mg} / \mathrm{L}$ & $\begin{array}{c}\text {-Sorbent selectivity against albumin from human } \\
\text { serum and conalbumin from chicken egg white } \\
\text { was tested. } \\
\text { - The sorbent could be used for } 6 \\
\text { adsorption/desorption cycles (recovery }>70 \% \text { ). } \\
\text {-Antimicrobial activity for Escherichia coli, } \\
\text { Pseudomonas fluorescens, Staphylococcus aureus, and } \\
\text { Bacillus subtilis was studied. } \\
\text {-The method was applied to the analysis of fresh, } \\
\text { pasteurized, and powder milk samples. }\end{array}$ & [20] \\
\hline $\begin{array}{l}\text { Green tea } \\
(0.5 \mathrm{~g})\end{array}$ & $\begin{array}{l}\text { Epicatechin, } \\
\text { epigallocatechin } \\
\text { gallate, and } \\
\text { epicatechin gallate }\end{array}$ & $\begin{array}{c}\text { ChCl:glycerol@SiO }{ }_{2} @ \mathrm{Fe}_{3} \mathrm{O}_{4} \\
(1: 2 ; 15 \mathrm{mg})\end{array}$ & $m-\mu-d S P E$ & HPLC-UV & $\begin{array}{c}80-93 \\
-\end{array}$ & $\begin{array}{l}\text {-Urea, ethylene glycol, and 1,4-butanediol were also } \\
\text { studied as HBDs. } \\
\text {-Ethanol was used as back-extraction solvent. } \\
-\mathrm{SiO}_{2} @ \mathrm{Fe}_{3} \mathrm{O}_{4} \text {-based DES, MIPs, and NIP extraction } \\
\text { performances were compared. } \\
\text { - The method was also applied to the analysis of three } \\
\text { tanshinones in Salvia miltiorrhiza bunge and three } \\
\text { isoflavones in Glycine max (Linn.) Merr. }\end{array}$ & [22] \\
\hline
\end{tabular}

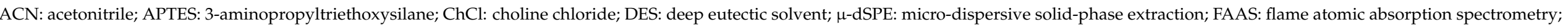

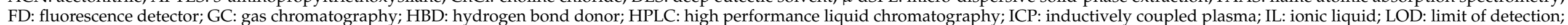

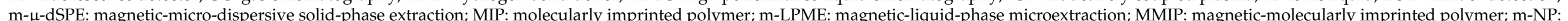

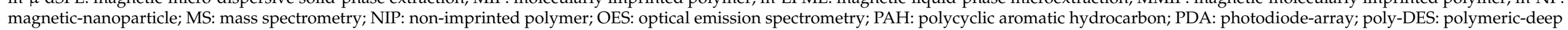

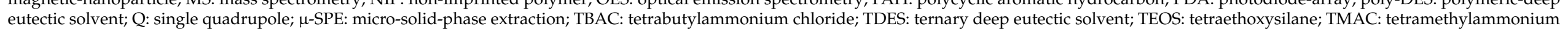
chloride; ToF: time of flight; UA: ultrasound-assisted; UHPLC: ultra-high performance liquid chromatography; UV: ultraviolet; VA: vortex-assisted. 
The DESs commented above have been used as carriers, modifiers, and dispersers of different nanomaterials, or as acceptor phases of the extraction sorbent. In this regard, they have been applied as ferrofluids, suspensions of magnetic nanomaterials (usually coated with a surfactant) in a carrier solvent, in which DESs can act not only as carrier/support solvent but also as the extractant phase or disperser. These applications include their combinations with pristine $\mathrm{Fe}_{3} \mathrm{O}_{4}$ m-NPs [37,38] or functionalized with TEOS [15], oleic acid [13], or polydopamine [14], and $\mathrm{SiO}_{2} @ \mathrm{Fe}_{3} \mathrm{O}_{4} \mathrm{~m}-\mathrm{NPs}$ [16] since the agglomeration of the NPs could be avoided thanks to the characteristically high viscosity of DESs, increasing the extraction efficiency as a result of the slow sedimentation of the NPs [39]. As an example, Dil et al. [13] developed a vortex-assisted (VA)-magnetic-liquid-phase microextraction (mLPME) based on a hydrophobic ferrofluid of DL-menthol:octanoic acid@oleic acid- $\mathrm{Fe}_{3} \mathrm{O}_{4}$ m-NPs for the extraction of doxycycline from urine, blood plasma, and milk samples. In this case, the HDES played a dual role, as a carrier solvent and as an acceptor phase. The ferrofluid was synthesized by diffusing $50 \mathrm{mg}$ of oleic acid- $\mathrm{Fe}_{3} \mathrm{O}_{4} \mathrm{~m}-\mathrm{NPs}$ into $1 \mathrm{~mL}$ of HDES. Then, $150 \mu \mathrm{L}$ of the ferrofluid was used to extract the mentioned antibiotic from $10 \mathrm{~mL}$ of sample solution. After the agitation and ferrofluid isolation by an external magnet, $50 \mu \mathrm{L}$ of methanol was utilized to re-extract the analyte from the sorbent. The final extract was injected into the high-performance liquid chromatography (HPLC)-UV system achieving recovery values of $87-94 \%$ and a limit of detection (LOD) of $3.6 \mu \mathrm{g} / \mathrm{L}$. In this work, the use of an HDES allowed increasing the mass transfer which is faster in a liquid phase than in the solid phase of the sorbent. Additionally, the use of a vortex improved the dispersion of the magnetic nanofluid into the sample solution.

On the contrary, Majidi, and Hadjmohammadi. [16] synthesized a ferrofluid formed by a DES of TMAC:ethylene glycol (1:3) and m-NPs of $\mathrm{SiO}_{2} @ \mathrm{Fe}_{3} \mathrm{O}_{4}$. The hydrophilic DES used acted as a carrier and disperser. Hence, it not only improved the dispersion of the sorbent into the sample solution (while the DES is dissolved into the aqueous solution) but also prevented the aggregation of the NPs. Moreover, the DES contained 20\% methanol $(v / v)$ in order to reduce its viscosity and, consequently, enhance the dispersion (and mass transfer) of the ferrofluid. Under optimum conditions: $7 \mathrm{mg}$ of m-NPs supported by $150 \mu \mathrm{L}$ of DES, $10 \mathrm{~mL}$ of sample solution and $250 \mu \mathrm{L}$ of ethanol as back-extraction solvent, the method was applied to the analysis of the flavonoid morin in apple and grape juices, green tea, and onion. An LOD of $0.91 \mu \mathrm{g} / \mathrm{L}$ and recovery values in the range 83-99\% were obtained. Afterward, the methods with the DES as a carrier and without DES were compared, showing that the recovery of morin fell to $56 \%$ for the latter. This fact demonstrated the key role of DES in extraction efficiency.

These two approaches, the use of hydrophilic or hydrophobic ferrofluids, described the main solutions to enhance the extraction performance of DESs-based magnetic nanofluids. Nevertheless, a great variety of approaches have been performed in order to improve the procedures and increase their simplicity. In a very simple strategy, Piao et al. [18] developed an extraction procedure based on the in-situ formation of a hydrophilic ferrofluid for the extraction of desmetryn, secbumeton, terbumeton, terbuthylazine, and prometryn from rice samples. In this way, $250 \mu \mathrm{L}$ of DES composed of TBAC:ethylene glycol at a molar ratio of 1:2 was added to $4 \mathrm{~mL}$ of hexane solution (containing the extract of $1 \mathrm{~g}$ of rice) and vortexed to disperse the solvent. Then, $40 \mathrm{mg}$ of $\mathrm{FeCl}_{3}$ was added to the sample solution and shaken to homogenize it. At this point, the ferrofluid was synthesized through the formation of the paramagnetic $\mathrm{FeCl}_{4^{-}}$anion. However, in order to improve its magnetic power, $90 \mathrm{mg}$ of carbonyl iron was added. After the magnetic separation, $5 \mathrm{~mL}$ of diethyl ether was added as re-extraction solvent, dried, and the final extract was re-dissolved in $100 \mu \mathrm{L}$ of acetonitrile (ACN) for its injection into the HPLC-UV/Visible system. The developed method provided LODs in the range 1.49-3.10 $\mu \mathrm{g} / \mathrm{kg}$, lower than the maximum residue levels established by the European Commission, and recovery values between $85 \%$ and $117 \%$. Besides, in order to check the reliability of the methodology, a maize sample was also evaluated obtaining a recovery in the range $78-105 \%$ with relative standard deviations 
lower than $9 \%$, demonstrating the applicability of the developed protocol to other cereal samples.

Regarding the application of MIPs for food analysis, DESs have been used as a functional monomer (those containing a component with an unsaturated bond) and as modifiers to improve the extraction performance of MIPs. These materials can present some drawbacks such as poor molecular recognition, slow extraction kinetic, and possible sample cross-contamination because of template bleeding [40]. Besides, sometimes target compounds and template molecules are poorly soluble in MIP precursors [24]. Thus, the tunable properties of DESs can improve MIPs extraction capacity, affinity, and selectivity. As functional additives, DESs enhance the hydrogen bond formation between the functional monomer and the template, while if they are used as functional monomers, DESs provide additional interactions through the extra-functional groups resulting in more active binding sites [39]. In this way, an NADES formed by caffeic acid (in addition to $\mathrm{ChCl}$ and ethylene glycol) [19] and a DES of acrylic acid (with $\mathrm{ChCl}$ ) [20] as polymerizable compounds have been applied. In the first case, $\mathrm{Li}$ et al. [19] prepared an MMIP using boron nitride as scaffold material and an NADES of $\mathrm{ChCl}$ :caffeic acid:ethylene glycol at a molar ratio of 5:1:5 as functional monomer. The magnetic sorbent was applied for the selective extraction of three flavonoids, including quercetin, isorhamnetin, and kaempferol, from Ginkgo biloba leaves prior to its determination by HPLC-UV detection. In another work, Fu et al. [20] not only explored a DES-based MIP for the selective recognition of $\beta$-lactoglobulin in milk samples but also its potential as antibacterial material. In this regard, $\mathrm{ChCl}$ :acrylic acid at a molar ratio of 1:2 was used as functional monomer while $\mathrm{MoS}_{2}$ was selected as base nanomaterial. This adsorbent showed inhibition of $65 \%$ for Escherichia coli, 50\% for Staphylococcus aureus, and 54\% for Bacillus subtilis. However, since $\mathrm{ChCl}$ (vitamin B member) is a common nutrient, the synthesized MIP promoted the growth of Pseudomonas fluorescens bacteria.

In a more sustainable design, Tan et al. [23] prepared an MMIP using a DES of $\mathrm{ChCl}$ :caffeic acid:formic acid, as functional monomer, and zein as the cross-linker. In this case, compared with the typical use of ethylene glycol dimethacrylate as crosslinking agent $[19,20,22]$ and 2,2-azobisisobutyronitrile $[19,22]$ or benzoyl peroxide/N,N-dimethylaniline [20] initiators, the use of zein as a self-polymerizable substance in water made it possible to avoid the use of initiators employing a natural plant protein-based biodegradable and biocompatible cross-linker. Whereas, the DES provided HBA/HBD sites to interact with the target analyte through the carboxylic or amine groups. While the lack of DES did not allow to establish enough interactions with the template, too much DES formed a thin layer of polymer blocking the cavities of the MMIP. Thus, using an appropriate volume of $2 \mathrm{~mL}$ for the performance of MMIPs modified magnetic glassy carbon electrode, recovery values of aspartame in drinks of $85-107 \%$ were achieved.

Furthermore, ChCl-based NADESs of glycerol [22] or urea [21] have been employed as functional additives to improve the characteristics of MIPs. According to Li et al. [22], the combination of DESs with MMIPs provides higher affinity capacity and selectivity of the sorbent through the formation of porosity and its better aqueous compatibility. Thus, the molecular recognition of MIPs, together with the magnetic assistance of the m-NPs, and the aqueous affinity of DESs provided a promising material for extraction. The authors compared the extraction ability of four DES-based MMIPs with the ones shown by nonDES-based MMIPs and non-imprinted polymers (NIPs) for the extraction of epicatechin, epigallocatechin gallate, and epicatechin gallate from green tea, demonstrating that, the best extraction capacities were those obtained with DES-based MIPs by a significant margin. As can be seen in Figure 1, the application of DESs with MMIPs for the extraction of such compounds provided a clear improvement of the final HPLC-UV chromatogram. In addition, the same sorbents were applied for the analysis of Tanshinone I and IIA, and cryptotanshinone from Salvia miltiorrhiza Bunge and glycitein, genistein, and daizein from Glycine max (Linn.) Merr. providing similar results. 


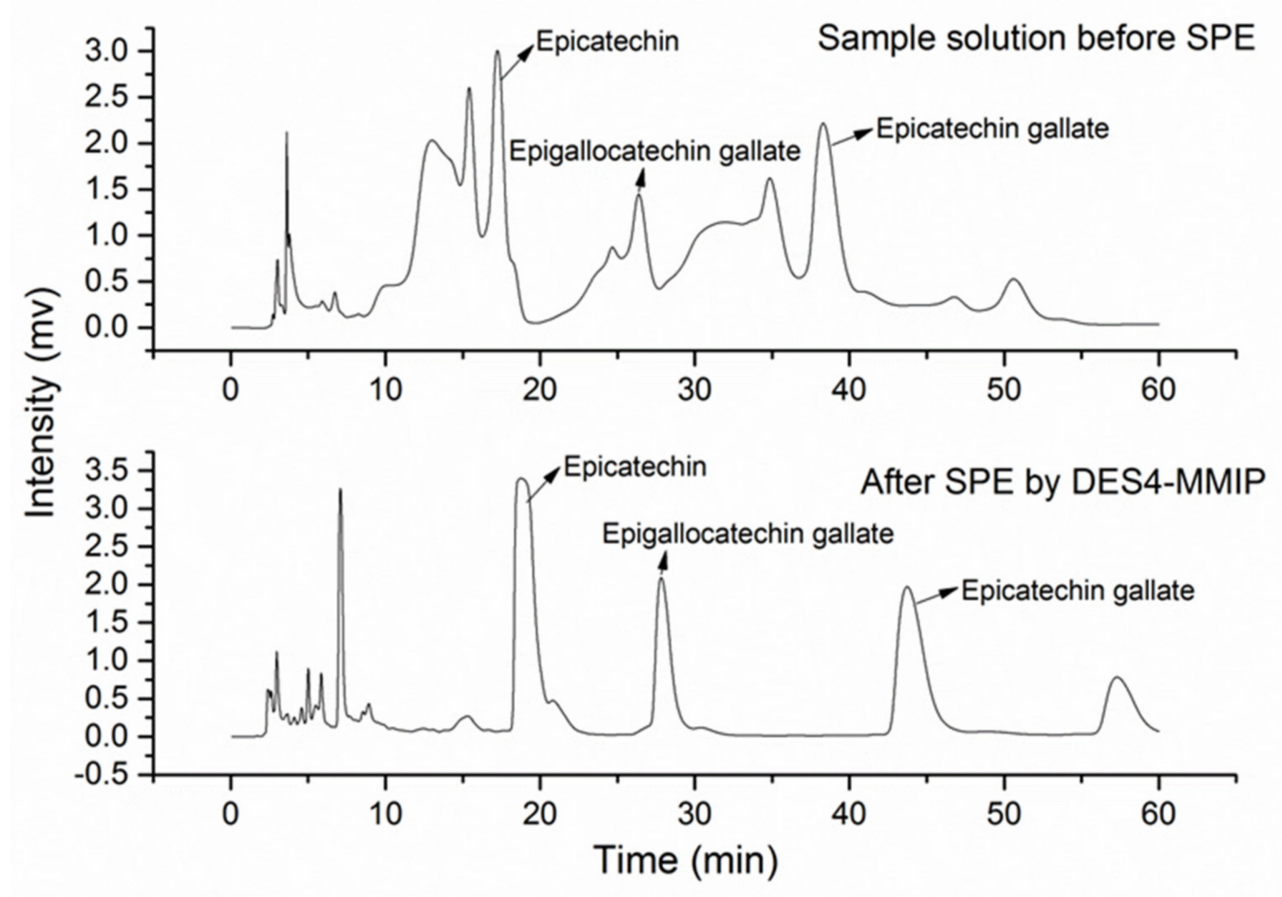

Figure 1. HPLC-UV chromatogram of epicatechin, epigallocatechin gallate, and epicatechin gallate after their extraction from green tea using DES4-MMIP in which DES4 was constituted by $\mathrm{ChCl}$ and glycerol at a molar ratio of 1:2. Reprinted from Li, G.; Wang, X.; Row, K. H. Magnetic molecularly imprinted polymers based on silica modified by deep eutectic solvents for the rapid simultaneous magnetic-based solid-phase extraction of Salvia miltiorrhiza bunge, Glycine max (Linn.) Merr and green tea. Electrophoresis, 2018, 39 (8), 1111-1118 with permission from Wiley [22].

Even though in some cases it seems that good extraction performance has been achieved, the fact that hydrophilic DESs have been used as extractant phase in aqueous solutions raises some doubts since these DESs decompose in aqueous samples. For example, this is the case of the work of Kasa et al. [37], who prepared a ferrofluid of ChCl:phenol (1:3)@ $\mathrm{Fe}_{3} \mathrm{O}_{4}$ for the preconcentration of cadmium from eucalyptus and rosemary tea samples and determination by the slotted quartz tube-flame atomic absorption spectrometry (FAAS). To a great extent, the contradictions that exist between articles regarding the use of hydrophilic DESs as an acceptor phase in sorbents used for the analysis of aqueous samples or solutions is due to the lack of characterization of the sorbents before and after the extraction. In fact, such characterization must demonstrate that, in those cases in which DESs are the main driving force of extraction, the components remain in that final phase. Furthermore, there is a lack of studies comparing the efficiencies of m-NPs or "naked sorbents" with their DESs-functionalized structures. In this way, the need to incorporate a DES would be justified and demonstrated.

DESs-based m-NPs have been used in food analysis in both liquid-phase microextraction and solid-phase extraction (SPE) approaches. In the first case, m-LPME $[13,15,38]$ has been the most used while magnetic-micro-dispersive solid-phase extraction (m- $\mu$-dSPE) [14, $16,18,19,22,37]$ has been preferred for solid adsorbents, although micro-dispersive SPE ( $\mu$ dSPE) [20] and micro-SPE ( $\mu$-SPE) [21] have also been applied. Nevertheless, in the last two cases, the sorbent is based on m-NPs and, considering that no comparison of the modified and unmodified sorbents was carried out, the use of the magnetic core is not justified. In addition to the magnetic assistance, other supplementary aids have been employed, including VA [13] and ultrasound-assistance (UA) [14,15], with the aim of improving the dispersion of the sorbent into the sample solution as well as enhancing the mass transfer. Generally, after the extraction process, different back-extraction solvents have been utilized depending on the analytes affinity and the separation/determination system. Regarding the analytical techniques, liquid chromatography (LC) coupled to conventional detection 
systems, such as UV [13,16,19,21,22], UV/Visible [18,20], and photodiode array (PDA) [14] detectors, stand out for the determination of organic compounds, although one application of ultra-high performance liquid chromatography (UHPLC) coupled to mass spectrometry (MS) for the analysis of perfluoroalkyl substances in edible oils [38] and one of gas chromatography (GC)-MS for the determination of PAHs in grilled meats can also be found in the literature [15]. This can be explained due to the generally low volatility of DESs that possibly can contaminate/damage the chromatographic equipment such as the MS detector or the GC injector. In the case of inorganic species, FAAS [37] has been used so far and for aspartame in soft drinks, an MMIP modified electrode was used in differential pulse voltammetry measurements [23].

\subsection{Combination of MOFs and Carbon-Based Nanomaterials with DESs}

As previously described for m-NPs, the excellent properties exhibited by DESs have allowed their use as modifiers of other solid sorbents such as MOFs and carbon-based nanomaterials and their subsequent application as extraction agents in (micro)extraction techniques have attracted much attention in food analysis in recent years. As can be seen in Table 2 [25-36], these functionalized materials have been applied for the extraction of organic compounds, including contaminants such as phthalic acid esters (PAEs) [25], pharmaceuticals [27,36], dyes [28,32], pesticides [29,34,35], and biomolecules such as RNA [26] and flavonoids [30], as well as heavy metals such as cadmium [31,33], lead [33], copper [33], and arsenic [33] from a wide variety of food matrices, including dairy products (yogurt [25] and milk [33]), beverages (water [25,31], juices [32,33] and tea [30,33]), soybean oil [25], medicinal yeast [26], plant tissue [27], animal-derived products (fish [28,31], chicken [31], and cow meat [31]), hotpot condiment and chilli paste [36], jelly powder [32], fruits (lemon, apricot and peach [31]), cereals (rice [33]), vegetables (tomato paste and spinach [33]), dried fruits (walnut [33]), kelp and seaweed [35], beebread, Curcuma wenyujin, and Dendrobium officinale [29].

The modification of MOFs and carbon-based nanomaterials by DESs minimize the agglomeration of these materials and provide good dispersibility and stability in the sample solution. The types of DESs commonly used for this purpose have been hydrophilic BDESs, mainly those composed of $\mathrm{ChCl}[25,30,31,33,34,36]$, although other quaternary ammonium salts (QAs) such as TBAC [26], benzyltributylammonium chloride (BTBAC) [27], TMAC [32], and betaine [29] have also been applied as HBAs, combined with different HBDs such as alcohols (glycerol [25,29,31] and ethylene glycol [30]), carboxylic acids (lactic acid [26,27]), and amides (urea [32,36], thioacetamide [33] and 2-pyridinecarboxamide [34]). Besides, poly-DESs and TDESs have also been developed to modify MOFs and carbonbased nanomaterials, respectively $[28,35]$.

Regarding the extraction techniques, SPE methods, including pipette tip (PT)-SPE [30], $\mu$-dSPE [29,35], and m- $\mu$-dSPE [26-28,31,32], have been the most common approaches in this field. Although, to a lesser extent, m-LPME methods have also been reported [33,34]. Likewise, an SPME procedure using a fiber prepared from UMCM-1@MIP and ChCl:glycerol (at a molar ratio of 1:2) for the extraction of PAEs from food samples has also been investigated [25]. Occasionally, these procedures have been aided by shaker (SA) $[26,27]$ or UA [34] agitation methods, as well as air cycles of pulling in/pushing out [33]. With respect to the analytical techniques, the separation and quantification of organic compounds have been carried out by GC $[25,34]$ and LC $[29,30,35]$ coupled to both conventional detectors $[25,29,30]$ and MS systems $[34,35]$, as well as by spectrophotometric methods [26-28,32,36], while metal ions have been analyzed by atomic absorption spectrometric methods $[31,33]$. 
Table 2. Some examples of the application of innovative combinations of MOFs and carbon-based nanomaterials with DESs in food analysis.

\begin{tabular}{|c|c|c|c|c|c|c|c|}
\hline $\begin{array}{l}\text { Sample } \\
\text { (Amount) }\end{array}$ & Analytes & $\begin{array}{c}\text { Sorbent } \\
\text { (DES Molar Ratio; Amount) }\end{array}$ & $\begin{array}{l}\text { Extraction } \\
\text { Procedure }\end{array}$ & $\begin{array}{l}\text { Analytical } \\
\text { Technique }\end{array}$ & Recovery \%LOD & Comments & Reference \\
\hline \multicolumn{8}{|c|}{ MOFs } \\
\hline $\begin{array}{l}\text { Yogurt, water and } \\
\text { edible oil } \\
(-)\end{array}$ & 4 PAEs & $\begin{array}{c}\text { ChCl:glycerol@UMCM- } \\
\text { 1@MIP } \\
(1: 2 ;-)\end{array}$ & HF-LMP-SPME & GC-FID & $\begin{array}{c}95-100 \\
0.008-0.030 \mu \mathrm{g} / \mathrm{L}\end{array}$ & $\begin{array}{l}\text {-Hollow and SPME fibers could be reused } \\
\text { more than } 80 \text { times. } \\
\text {-The method was applied to the analysis of } \\
\text { yogurt, edible soybean oil, and bottled } \\
\text { mineral water samples. }\end{array}$ & [25] \\
\hline $\begin{array}{l}\text { Medicinal yeast } \\
\quad(5.0 \mathrm{~g})\end{array}$ & RNA & $\begin{array}{c}\text { TBAC:lactic acid@UiO-66- } \\
\mathrm{NH}_{2} @ \mathrm{Fe}_{3} \mathrm{O}_{4}-\mathrm{COOH} \\
(1: 2 ; 5 \mathrm{mg})\end{array}$ & SA-m- $\mu-d S P E$ & $\begin{array}{c}\text { UV/Visible } \\
\text { spectrophotometry }\end{array}$ & - & $\begin{array}{c}\text {-Four DESs composed of different QASs as } \\
\text { HBAs and lactic acid as HBD, at a molar } \\
\text { ratio of } 1: 2 \text {, were evaluated. } \\
\text {-TBAC:lactic acid (1:2) was used as } \\
\text { back-extraction solvent. } \\
\text {-DES@UiO-66- } \mathrm{NH}_{2} @ \mathrm{Fe}_{3} \mathrm{O}_{4} \text {, } \\
\text { UiO-66- } \mathrm{NH}_{2} @ \mathrm{Fe}_{3} \mathrm{O}_{4} \text { and } \mathrm{Fe}_{3} \mathrm{O}_{4} \mathrm{NPs} \\
\text { based-extractions were compared. } \\
\text {-A selectivity study was carried out in the } \\
\text { presence of interfering substances. } \\
\text {-The sorbent could be used for six } \\
\text { adsorption/desorption cycles. }\end{array}$ & [26] \\
\hline $\begin{array}{l}\text { Plant tissue } \\
\quad(-)\end{array}$ & 5 Pharmaceuticals & $\begin{array}{c}\text { BTBAC:lactic acid@UiO-66- } \\
\mathrm{NH}_{2} @ \mathrm{Fe}_{3} \mathrm{O}_{4}-\mathrm{COOH} \\
(1: 2 ; 5 \mathrm{mg})\end{array}$ & SA-m- $\mu-d S P E$ & $\begin{array}{c}\text { UV/Visible } \\
\text { spectrophotometry }\end{array}$ & - & $\begin{array}{c}\text {-Seven DESs composed of different QASs } \\
\text { as HBAs and lactic acid or glycolic acid as } \\
\text { HBDs, at a molar ratio of } 1: 2 \text {, were } \\
\text { evaluated. } \\
\text {-Adsorption capacity was } 79.22 \mathrm{mg} / \mathrm{g} \text {. } \\
\text {-A selectivity study was carried out in the } \\
\text { presence of interfering ions. } \\
\text {-The sorbent could be used for six } \\
\text { adsorption/desorption cycles. }\end{array}$ & [27] \\
\hline $\begin{array}{l}\text { Fish } \\
(2.0 \mathrm{~g})\end{array}$ & $\begin{array}{l}\text { Malachite green } \\
\text { and violet crystal }\end{array}$ & $\begin{array}{c}\text { APTMAC:D- } \\
\text { sorbitol@HKUST-1@NH } 2_{2-}^{-} \\
\mathrm{Fe}_{3} \mathrm{O}_{4} \\
(2: 1 ; 5 \mathrm{mg})\end{array}$ & $\mathrm{m}-\mu-\mathrm{dSPE}$ & $\begin{array}{c}\text { UV/Visible } \\
\text { spectrophotometry }\end{array}$ & $\begin{array}{c}89-101 \\
24.0-98.2 \mu \mathrm{g} / \mathrm{L}\end{array}$ & $\begin{array}{l}\text {-Methanol was used as back-extraction } \\
\text { solvent. } \\
\text {-Poly-DES@HKUST-1@NH } \mathrm{NH}_{2}-\mathrm{Fe}_{3} \mathrm{O}_{4} \\
\text { HKUST-1@NH } \mathrm{NH}_{2}-\mathrm{Fe}_{3} \mathrm{O}_{4} \text { and } \mathrm{NH}_{2}-\mathrm{Fe}_{3} \mathrm{O}_{4} \\
\text { extraction performances were compared. } \\
\text {-A selectivity study between cationic and } \\
\text { anionic dyes was developed. } \\
\text {-The sorbent could be used for five } \\
\text { adsorption/desorption cycles. }\end{array}$ & [28] \\
\hline
\end{tabular}


Table 2. Cont.

\begin{tabular}{|c|c|c|c|c|c|c|c|}
\hline $\begin{array}{l}\text { Sample } \\
\text { (Amount) }\end{array}$ & Analytes & $\begin{array}{c}\text { Sorbent } \\
\text { (DES Molar Ratio; Amount) }\end{array}$ & $\begin{array}{l}\text { Extraction } \\
\text { Procedure }\end{array}$ & $\begin{array}{l}\text { Analytical } \\
\text { Technique }\end{array}$ & Recovery \%LOD & Comments & Reference \\
\hline \multicolumn{8}{|c|}{ Carbon-based nanomaterials } \\
\hline $\begin{array}{l}\text { Hotpot condiment and } \\
\text { chilli paste } \\
\text { (1 g) }\end{array}$ & Morphine & $\begin{array}{c}\mathrm{N}, \mathrm{Cl} \text { co-doped carbon dots } \\
(-;-)\end{array}$ & - & FD & $\begin{array}{c}95-103 \\
46.5 \mu \mathrm{g} / \mathrm{L}\end{array}$ & $\begin{array}{l}\text {-DES was formed by mixing } 0.61 \mathrm{~g} \text { of } \mathrm{ChCl} \\
\text { and } 1.39 \mathrm{~g} \text { of urea. } \\
\text {-Sorbent selectivity against interfering } \\
\text { substances and analogs was evaluated. }\end{array}$ & [36] \\
\hline $\begin{array}{l}\text { Fruit juice and jelly } \\
\text { powder } \\
(-)\end{array}$ & $\begin{array}{l}\text { Indigotin blue } \\
\text { dye }\end{array}$ & $\begin{array}{l}\text { TMAC:urea@m-GO } \\
\quad(-; 10 \mathrm{mg})\end{array}$ & $\mathrm{m}-\mu-\mathrm{dSPE}$ & $\begin{array}{c}\text { UV/Visible } \\
\text { spectrophotometry }\end{array}$ & $\begin{array}{c}96-102 \\
1.5 \mu \mathrm{g} / \mathrm{L}\end{array}$ & $\begin{array}{l}\text {-DES was formed by mixing } 1 \mathrm{~g} \text { of each } \\
\text { component. } \\
\text {-Methanol was used as back-extraction } \\
\text { solvent }(1 \mathrm{~mL}) \text {. } \\
\text {-The sorbent cannot be reused. }\end{array}$ & [32] \\
\hline $\begin{array}{l}\text { Water, fruit and meat } \\
\qquad(-)\end{array}$ & $\mathrm{Cd}(\mathrm{II})$ & $\begin{array}{c}\text { ChCl:glycerol@pyridine } \\
\text { ligand@m-GO } \\
(1: 1 ; 10 \mathrm{mg})\end{array}$ & $\mathrm{m}-\mu$-dSPE & Flow injection-FAAS & $\begin{array}{c}95-105 \\
0.06 \mu \mathrm{g} / \mathrm{L}\end{array}$ & $\begin{array}{c}-\mathrm{HNO}_{3}(2.5 \mathrm{M}) \text { was used as } \\
\text { back-extraction solvent }(200 \mu \mathrm{L}) \text {. } \\
\text {-Modified m-GO and bare m-GO extraction } \\
\text { performances were compared. } \\
\text {-A selectivity study was carried out in the } \\
\text { presence of interfering ions. } \\
\text {-The method was applied to the analysis of } \\
\text { drinking and river water, lemon, apricot } \\
\text { and peach, and fish, chicken, and cow } \\
\text { meat samples. } \\
\text {-A comparison with the results obtained } \\
\text { from ETAAS analysis was carried out. }\end{array}$ & [31] \\
\hline $\begin{array}{l}\text { Foodstuff } \\
(1.0-2.0 \mathrm{~g})\end{array}$ & $\begin{array}{c}\mathrm{Cd}(\mathrm{II}), \mathrm{Pb}(\mathrm{II}) \\
\mathrm{Cu}(\mathrm{II}) \text { and } \mathrm{As}(\mathrm{III})\end{array}$ & $\begin{array}{c}\text { ChCl:thioacetamide@m- } \\
\text { MWCNTs } \\
(1: 2 ; 40 \mu \mathrm{L})\end{array}$ & AA-m-LPME & ETAAS & $\begin{array}{c}94-101 \\
3.0-4.2 \mathrm{ng} / \mathrm{L}\end{array}$ & $\begin{array}{l}\text {-Urea and thiourea were also studied as } \\
\text { HBDs. } \\
\text {-Ferrofluid contained } 50 \text { mg of } \\
\text { m-MWCNTs and } 500 \mu \mathrm{L} \text { of DES. } \\
\text {-Six pulling in/pushing out air cycles were } \\
\text { carried out. } \\
\text { - } \mathrm{HNO}_{3}(1 \mathrm{M}) \text { was used as back-extraction } \\
\text { solvent ( } 75 \mu \mathrm{L}) \text {. } \\
\text {-A selectivity study was carried out in the } \\
\text { presence of interfering ions. } \\
\text {-The method was applied to the analysis of } \\
\text { rice, tomato paste, spinach, orange juice, } \\
\text { walnut, and black tea samples, as well as } \\
\text { environmental water samples. }\end{array}$ & [33] \\
\hline
\end{tabular}


Table 2. Cont.

\begin{tabular}{|c|c|c|c|c|c|c|c|}
\hline $\begin{array}{l}\text { Sample } \\
\text { (Amount) }\end{array}$ & Analytes & $\begin{array}{c}\text { Sorbent } \\
\text { (DES Molar Ratio; Amount) }\end{array}$ & $\begin{array}{l}\text { Extraction } \\
\text { Procedure }\end{array}$ & $\begin{array}{l}\text { Analytical } \\
\text { Technique }\end{array}$ & Recovery \%LOD & Comments & Reference \\
\hline \multicolumn{8}{|c|}{ Carbon-based nanomaterials } \\
\hline $\begin{array}{l}\text { Tea } \\
(5.0 \mathrm{~g})\end{array}$ & $\begin{array}{l}\text { Myricetin and } \\
\text { rutin }\end{array}$ & $\begin{array}{c}\text { ChCl:ethylene glycol@N-GO } \\
\text { (1:2; } 3 \mathrm{mg})\end{array}$ & PT-SPE & HPLC-UV & $\begin{array}{c}71-100 \\
5.46-24.7 \mu \mathrm{g} / \mathrm{L}\end{array}$ & $\begin{array}{l}\text {-Dimethyl sulfoxide/acetic acid }(9: 1, v / v) \\
\text { was used as back-extraction solvent }(1 \mathrm{~mL}) \text {. } \\
\text {-DES@N-GO, DES@B-GO, N-GO, B-GO } \\
\text { and GO extraction performances were } \\
\text { compared. }\end{array}$ & [30] \\
\hline $\begin{array}{l}\text { Milk } \\
(20 \mathrm{~mL})\end{array}$ & $\begin{array}{l}3 \text { Pyrethroid } \\
\text { insecticides }\end{array}$ & $\begin{array}{l}\text { ChCl:2- } \\
\text { pyridinecarboxamide:FeCl } @ \text { m- } \\
\text { MWCNTs } \\
(3: 4: 1 ; 50 \mu \mathrm{L})\end{array}$ & UA-m-LPME & GC-QqQ-MS & $\begin{array}{c}91-105 \\
2.0-2.8 \mu \mathrm{g} / \mathrm{L}\end{array}$ & $\begin{array}{c}\text {-Ferrofluid contained } 50 \mathrm{mg} \text { of } \\
\text { m-MWCNTs and } 500 \mu \mathrm{L} \text { of DES. } \\
\text {-Acetone was used as back-extraction } \\
\text { solvent }(100 \mu \mathrm{L}) \text {. } \\
\text {-The method was applied to the analysis of } \\
\text { bovine and pasteurized milk samples. }\end{array}$ & [34] \\
\hline $\begin{array}{c}\text { Kelp and seaweed } \\
(-)\end{array}$ & 4 Bromophenols & $\begin{array}{l}\text { Dodecyl dimethyl betaine:1,3- } \\
\text { propanediol:glycerol@MWCNTs } \\
\quad(1: 1: 1 ; 2.0 \mu \mathrm{g} / \mathrm{mL})\end{array}$ & $\mu$-dSPE & UHPLC-Q-ToF-MS & $\begin{array}{c}85-98 \\
0.12-0.60 \mu \mathrm{g} / \mathrm{L}\end{array}$ & $\begin{array}{l}\text {-Other long-chain betaine-based DESs } \\
\text { were evaluated. } \\
\text {-Adsorption isotherm and kinetic studies } \\
\text { were performed. }\end{array}$ & [35] \\
\hline$\underset{(-)}{\text { Natural products }}$ & $\begin{array}{l}5 \text { Pyrethroid } \\
\text { insecticides }\end{array}$ & $\begin{array}{l}\text { Betaine:glycerol@GO } \\
\quad(1: 2 ; 1.5 \mu \mathrm{g} / \mathrm{mL})\end{array}$ & $\mu$-dSPE & UHPLC-DAD & $\begin{array}{c}81-113 \\
0.016-0.240 \mu \mathrm{g} / \mathrm{L}\end{array}$ & $\begin{array}{c}\text {-ChCl and betaine as HBAs combined with } \\
\text { sugars, alcohols and urea as HBDs were } \\
\text { evaluated at different molar ratios. } \\
\text {-Other types of graphene were evaluated, } \\
\text { including r-GO-tetraethylene pentamine } \\
\text { and carboxyl functionalized GO. } \\
\text {-ACN was used as back-extraction solvent } \\
\text { (100 } \mu \mathrm{L}) \text {. } \\
\text {-The method was applied to the analysis of } \\
\text { beebread, Curcuma wenyujin and } \\
\text { Dendrobium officinale samples. } \\
\text {-LC-MS/MS analysis were carried out to } \\
\text { confirm the obtained results. }\end{array}$ & [29] \\
\hline
\end{tabular}

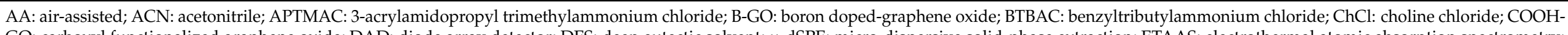

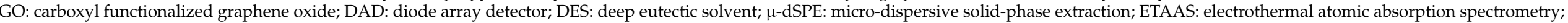

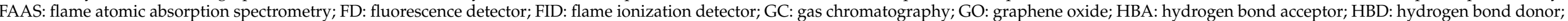

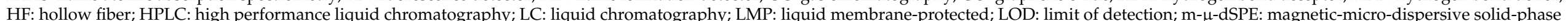

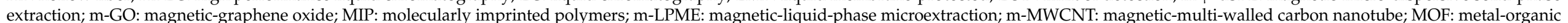

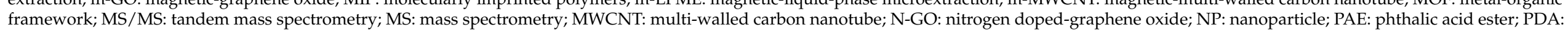

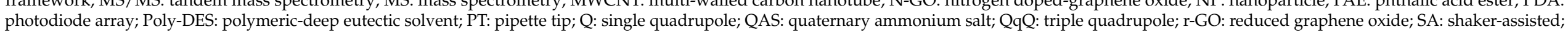

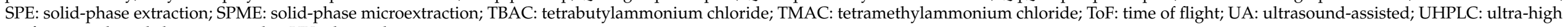
performance liquid chromatography; UV: ultraviolet. 
An interesting example of the functionalization of an MOF by a DES is the work carried out by Wei et al. [28]. In this case, the authors prepared an amino-magnetic $\left(\mathrm{NH}_{2}-\mathrm{Fe}_{3} \mathrm{O}_{4}\right)$-HKUST-1 and combined it with a poly-DES based on 3-acrylamidopropyl trimethylammonium chloride (APTMAC) as HBA and D-sorbitol as HBD, at a molar ratio of 2:1, for the removal of two cationic dyes, malachite green and violet crystal, from fish samples by $\mathrm{m}-\mu$-dSPE technique. This modification was possible thanks to the lone pair of electrons of the $\mathrm{N}$ atom of APTMAC that formed coordination bonds with the unsaturated copper sites of HKUST-1. Besides, the polymerization of the HBA double bond resulted in increased stability of the sorbent, as well as the improvement of the extraction performance due to the presence of additional active sites available for the sorption of target analytes. After a thorough characterization, the specificity of the removal process was evaluated in the presence of both cationic and anionic dyes, the spectrophotometric results showed that APTMAC:D-sorbitol@HKUST-1@NH $\mathrm{NH}_{2}-\mathrm{Fe}_{3} \mathrm{O}_{4}$ compared to HKUST-1@NH ${ }_{2}-$ $\mathrm{Fe}_{3} \mathrm{O}_{4}$ and $\mathrm{NH}_{2}-\mathrm{Fe}_{3} \mathrm{O}_{4}$, more selectively extracted the two target analytes, mainly due to electrostatic interactions, although hydrogen-bonding and acid-base interactions could also occur. Under the optimal experimental conditions, recovery values were achieved in the range $89-101 \%$ and LODs between 24.0 and $98.2 \mu \mathrm{g} / \mathrm{L}$. Following the trends of the green chemistry, the authors studied the reusability of the sorbent and found that it could be used up to five adsorption/desorption cycles without losing the extraction capacity.

Following the same strategy based on the synthesis of long-term stable functional sorbents, Ye et al. [35] evaluated the stability of MWCNTs modified by six different longchain betaine-based TDESs. The longest stability was shown by the TDES@MWCNTs composed of dodecyl dimethyl betaine:1,3-propanediol:glycerol, at a molar ratio of 1:1:1, since no floating particles were appreciated after a month of standing. Consequently, this sorbent was selected for the $\mu$-dSPE of four bromophenols from kelp and seaweed samples that were then separated and quantified by UHPLC coupled to MS analysis. The comprehensive characterization of the sorbent confirmed the successful coating of the TDES onto the MWCNTs surface obtained by mechanical milling. Based on these results, the authors attributed the better dispersibility and stability of the modified MWCNTs to the lower hydrophobicity caused by the removal of impurities and non-polar functional groups, as well as by the addition of a new hydrophilic oxygen-containing functional group, and to the exfoliation of the naked nanomaterial, respectively. After optimizing the $\mathrm{pH}$ extraction, the adsorption behavior of the modified sorbent was thoroughly assessed by adsorption isotherms and kinetic studies, finding adsorption capacities in the range $156-1720 \mathrm{mg} / \mathrm{g}$ for the target analytes. Finally, recovery values obtained in the range $85-98 \%$ and LODs between 0.12 and $0.60 \mu \mathrm{g} / \mathrm{L}$ demonstrated the method fit for its purpose.

However, as previously mentioned, simpler DESs have also been applied to modify these nanomaterials. As an example, Sun et al. [30] introduced a DES-based on ChCl:ethylene glycol (1:2) onto heteroatom doped-GO for the PT-SPE of two flavonoids, myricetin, and rutin from tea samples, followed by their HPLC-UV determination. Compared to unmodified GO, DES@nitrogen doped-GO (N-GO) and DES@boron doped-GO (B-GO) showed better adsorption capacities toward target analytes as can be seen in Figure 2, in which the curves of under equilibrium adsorption (A) and dynamic adsorption (B) for all analytes are shown. The authors explained these results due to the better lamellar structure exhibited by the modified GO sorbents since the introduction of the DES stabilized the electron repulsive force of the lone pair of electrons provided by the heteroatom, giving rise to higher specific surface area and more selective adsorption of compounds of interest. Likewise, the doping with $\mathrm{N}$ atoms resulted in a better dispersibility of the sorbent than with B atoms. Therefore, $\mathrm{ChCl}$ :ethylene glycol@N-GO was selected to fulfill the analytical purpose. After optimizing washing and elution solvents of the PT-SPE procedure, good recovery values were achieved (71-100\%) and LODs between 5.46 and $24.7 \mu \mathrm{g} / \mathrm{L}$, showing the feasibility of the method for the proposed application. 
A

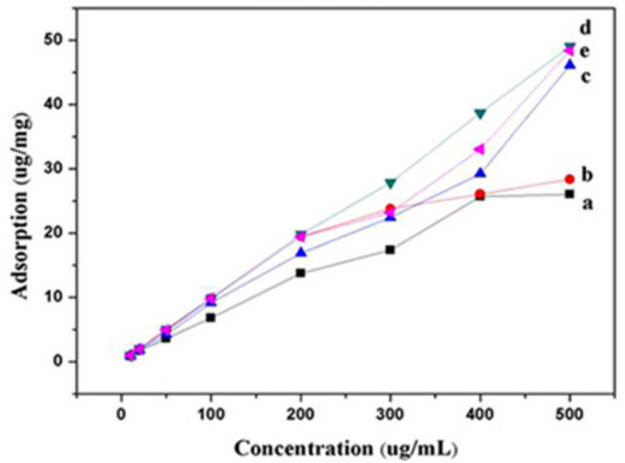

B

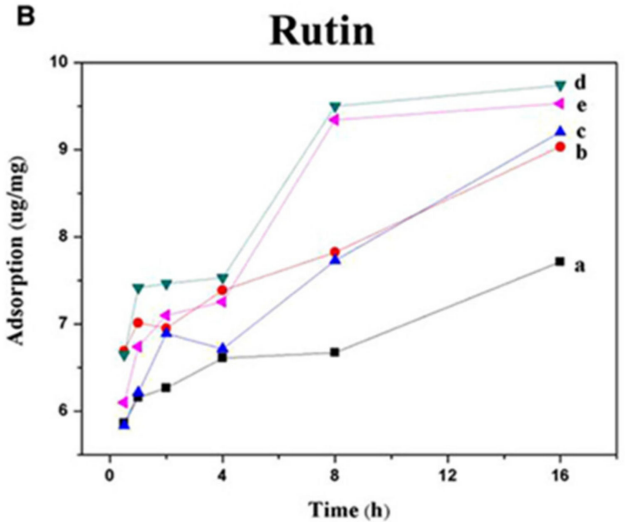

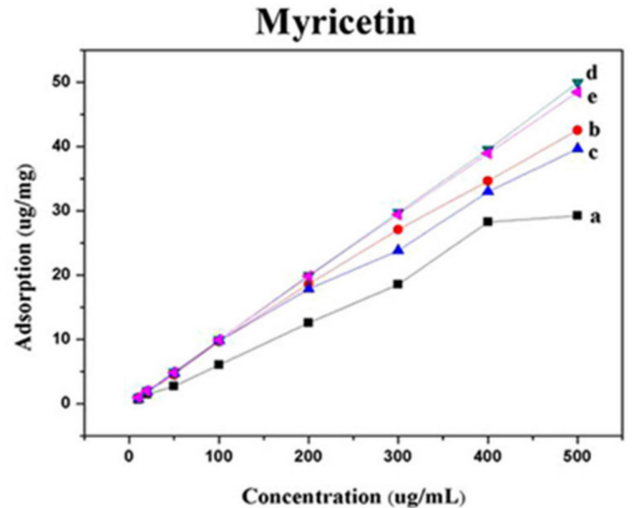

Myricetin

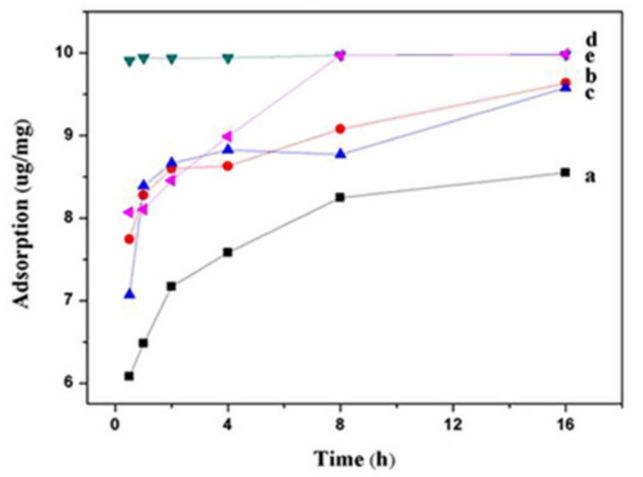

Figure 2. Adsorption equilibrium curves: (A) static adsorption capacity of GO (a), N-GO (b), B-GO (c), N-GO-DES (d) and B-GO-DES (e) in myricetin and rutin. (B) Dynamic adsorption capacity of GO (a), N-GO (b), B-GO (c), N-GO-DES (d) and B-GO-DES (e) in myricetin and rutin. Reprinted from Sun, L.; Deng, Q.; Zhu, T. Optimization of Heteroatom Doped Graphene Oxide by Deep Eutectic Solvents and the Application for Pipette-Tip Solid-Phase Extraction of Flavonoids. J. Sep. Sci., 2019, 42 (14), 2371-2378 with permission from Wiley [30].

In the same way, Song et al. [29] prepared six DESs from $\mathrm{ChCl}$ or betaine as $\mathrm{HBAs}$ and sugars, alcohols, or urea as HBDs, at different molar ratios, to functionalize graphene-based nanomaterials. Among them, only betaine:glycerol (1:2) and betaine:glycerol:propylene glycol (1:1:1) showed long-term stability. Consequently, both DESs were used to modify GO and then applied as extraction sorbent in the $\mu-\mathrm{dSPE}$ of five pyrethroid insecticides from natural products, prior to UHPLC-diode array detector (DAD) analysis. Although other graphene-based nanomaterials were tested, reduced-GO (r-GO)-tetraethylene pentamine and carboxyl functionalized GO, the best results were obtained by betaine:glycerol@GO due to the high solubility and stability of GO in the polyalcohol-based DES. Under optimized conditions, recovery values ranged from 81 to $114 \%$ and LODs between 0.016 and $0.240 \mu \mathrm{g} / \mathrm{L}$, which proved the suitability of the developed method for the analysis of pesticides in beebread, Curcuma wenyujin and Dendrobium officinale samples.

Apart from sorbent-based extraction techniques, DESs have also been combined with carbon-based nanomaterials to form nanofluids and apply them as extraction solvents in liquid-phase extraction methods. As an example, Shirani et al. [33] proposed the use of a magnetic nanofluid for the air-assisted (AA)-m-LPME (AA-m-LPME) of Cd (II), Pb (II), Cu (II), and As (III) from several foodstuffs (rice, tomato paste, spinach, orange juice, walnut, and black tea), as well as environmental water samples, prior to electrothermal atomic absorption spectrometry (ETAAS) analysis. The ferrofluid consisted of a mixture of a ChCl-based DES and magnetic-MWCNTs (m-MWCNTs). With this aim, different HBDs were evaluated, including urea, thiourea, and thioacetamide, at a molar ratio of 1:2. The highest extraction efficiency was provided by $\mathrm{ChCl}$ :thioacetamide, since the soft behavior of sulfur atoms and, consequently, its easy polarization, increased its affinity to metal ions 
and facilitated the interactions between them. This procedure stands out for the rapid and efficient mass transfer of analytes from the sample solution to the ferrofluid favored by six air cycles of pulling in/pushing out, so no additional disperser solvents were required. Besides, the magnetic behavior of the nanofluid avoided the centrifugation step since the final extract was separated by an external magnet. Finally, the method reached good results in terms of recovery values (94-101\%) and LODs (3.0-4.2 ng/L) after optimizing the process.

Finally, Yin et al. [36] carried out the synthesis of a different carbon-based nanostructure, $\mathrm{N}, \mathrm{Cl}$-doped carbon dots. This material, prepared from a DES of $\mathrm{ChCl}$ and urea, and glycine as the carbon source, was applied to the analysis of poppy shells in the hotpot condiment and chilli paste. The fluorescent probe provided an adequate sensitivity and selectivity for the quantification of morphine (as the main alkaloid of poppy shell). In this regard, an LOD of $46.5 \mu \mathrm{g} / \mathrm{L}$ and good recovery values between 95 and $103 \%$. For the detection of morphine, the synthesized carbon dots were 5 -fold diluted in water and $500 \mu \mathrm{L}$ were combined with a concentrated sample solution and then the fluorescent signal was measured. The presence of superficial amino groups enhances the emission intensity and the hydrogen-bonding interactions with morphine increase the surface electron density while stabilizing the surface and decreasing its defects. All of these produce the enhancement in the fluorescence intensity.

In summary, although still limited, the application of DESs as modifiers of MOFs and carbon-based nanomaterials has not only given rise to reduced aggregation, better dispersibility, and stability in an aqueous medium but also improved the adsorption capacity and selectivity of these sorbents. However, the characterization of these functionalized materials to check that the hydrophilic DES does not solubilize in contact with the aqueous sample solution, the study of their reusability to fulfill the requirements of the green chemistry, and their comparison with the corresponding unmodified material, as well as the introduction of HDESs, are important aspects that researchers should further address in this field.

\section{Conclusions}

The emergence of the application of nanomaterials in the field of analytical chemistry was a breakthrough not only in terms of the analytical procedure itself but also from the point of view of environmental and economic impact. With this, carbon-based nanomaterials, MOFs, NPs, m-NPs, and MIPs, among others, improved the previously developed procedures. However, the bottleneck in the development of this area is usually found in the use of toxic conventional solvents during synthesis processes. For this reason, the development of new liquid materials aimed at using solvents that are more sustainable and, therefore, less harmful, is essential. Still, further investigation of their characteristics is needed. Relatively close to GRAS solvents, DESs have been postulated as the new generation of solvents. Their various general properties, including their low toxicity, high biodegradability, and biocompatibility, high thermal stability, and low cost, establish them in the focus of many fields of study, including materials science.

Apart from their potential use as extraction solvents or modifiers of sensors and chromatographic systems, DESs have been combined with different sorbents, including m-NPs, MIPs, carbon-based nanomaterials, and MOFs, to improve the properties of these materials enhancing the selectivity, extraction capacity, and compatibility of the sorbents. Regarding the synthesis procedure of the DESs-based nanomaterials, most MDESs have been synthesized by a simple mixture of m-NPs with BDESs or TDESs, although applications of modified $\mathrm{m}$-NPs with different coatings or forming a core-shell $\mathrm{SiO}_{2}$-based material can also be found in the literature. Besides, the in-situ formation of the MDES during or after the extraction procedure has also been reported. Notwithstanding, and considering that most applications involving the use of MDESs have been aqueous solutions, the in-situ formation of hydrophilic MDESs in this medium seems to be cherry-picked, and their formation should be further investigated. In the case of MMIPs, the DESs have been 
employed as monomers or templates, in combination with m-NPs or alone. Concerning the combination of DESs with MOFs few applications can be found so far, whereas their combinations with carbon-based nanomaterials, mixtures of DESs with graphene, decorated or magnetic-GO, and m-MWCNTs can be found to occasion the desired materials. FTIR is the most common technique for the confirmation of DES formation while SEM is always involved for both MIPs, MOFs, and carbon-based nanomaterials. However, other techniques have been used with this purpose including XRD, VSM (when m-NPs are presented), TGA, BET surface analysis, among others. Despite all this, there is still a lack of "traceability" in the characterization of not only the structural integrity of the synthesized material during the extraction procedure but also throughout the synthesis procedure. In most cases, only the final sorbent is characterized and/or not thoroughly examined.

The unique properties of these solvents have allowed the use of nanomaterials combined with DESs in the field of food analysis. Both m-NPs and MIPs, as well as MOFs and carbon-based nanomaterials, have been used as extraction agents for the extraction of different organic pollutants (PAHs, pharmaceuticals, PAEs, dyes, and pesticides) and biomolecules (flavonoids, proteins, catechins, alkaloids, RNA), in addition to heavy metals from a wide variety of food samples (beverages, cereals, animal-derived products, dairy products, fruits and dried fruits, vegetables, edible and medicinal plants, and beebread, among others). DESs and NADESs, as well as poly-DESs and TDESs, have been used, being the $\mathrm{ChCl}$ the HBA utilized par excellence, although other QAs, as well as menthol, have also been chosen. Regarding the HBDs, different alcohols, medium-chain fatty acids or carboxylic acids, and amides have been employed.

In general, DESs give these materials improved properties and greater compatibility with aqueous samples added to the improvement in the adsorption capacity. In the case of m-NPs, the use of DESs avoids the agglomeration of the material due to their high viscosity resulting in slower sedimentation of the sorbent. For MIPs, DESs can improve the extraction capacity, affinity, and selectivity, and for MOFs and carbon-based nanomaterials, the combination with these solvents reduces the agglomeration, enhancing their dispersion and stability in aqueous samples.

Different approaches based on liquid-phase microextraction and SPE methods have been utilized. In this way, $\mathrm{m}-\mu$-dSPE has been the most used extraction protocol involving sorbents, although $\mu$-dSPE and $\mu$-SPE or PT-SPE have also been employed, and to a lesser extent, liquid-phase microextraction methods. In combination with these techniques, various mechanical assistances have been used such as vortex, ultrasounds, shaker, or air cycles, in addition to the magnetic assistance. All of them with the aim of improving the extraction performance. As regards the analytical techniques, LC stands out over GC in most cases coupled to conventional detectors although MS or direct by spectrophotometric methods have also been applied. In the case of metal species, atomic absorption spectrometric methods have been used.

The advantages offered by using nanomaterials in combination with DESs are undeniable. However, all that glitters is not gold. This refers to the fact that it is necessary to investigate in greater depth the introduction of a new component to the synthesis. Although DESs are considered green solvents, if a sorbent provides good extraction efficiency, it is not necessary to add another reagent just because it is more "saleable". This only causes the expenditure of resources to be greater, making the procedure more expensive and making the extraction system more complex, as well as its understanding. On the contrary, it is shown that it is essential to compare the modified and unmodified materials in terms of extractive potential in a way that shows whether or not there is the need to introduce a new component. Therefore, it could be said that the world of DESs is starting to take off and, for the reasonable and responsible use of them, a greater effort is needed to understand their behavior and properties.

Author Contributions: Conceptualization, B.S.-R. and J.A.P.; investigation, Á.S.-M.; resources, Á.S.M. and R.R.-R.; data curation, Á.S.-M., R.R.-R., B.S.-R., M.d.M.A. and J.A.P.; writing-original draft preparation, Á.S.-M., R.R.-R., B.S.-R., M.d.M.A. and J.A.P.; writing-review and editing, B.S.-R., 
M.d.M.A. and J.A.P.; visualization, Á.S.-M. and R.R.-R.; supervision, B.S.-R., M.d.M.A. and J.A.P.; project administration, M.d.M.A. and J.A.P.; funding acquisition, M.d.M.A. and J.A.P. All authors have read and agreed to the published version of the manuscript.

Funding: This work has been funded by the Spanish Ministry of Economy, Industry and Competitiveness (project AGL2017-89257-P).

Acknowledgments: Á.S.-M. and R.R.-R. would like to thank the Canary Agency of Economy, Industry, Trade and Knowledge of the Government of the Canary Islands for the FPI fellowship (co-financed from Agencia Canaria de Investigación, Innovación y Sociedad de la Información de la Consejería de Economía, Conocimiento y Empleo y por el Fondo Social Europeo (FSE) Programa Operativo Integrado de Canarias 2014-2020, Eje 3 Tema Prioritario 74 (85\%)).

Conflicts of Interest: The authors declare no conflict of interest.

\section{References}

1. United Nations. A/RES/70/1-Transforming Our World: The 2030 Agenda for Sustainable Development. 2015. Available online: https://www.un.org/en/development/desa/population/migration/generalassembly/docs/globalcompact/A_RES_ 70_1_E.pdf (accessed on 24 November 2021).

2. FoodDrinkEurope. Data \& Trends of the EU Food and Drink Industry. Available online: https://www.fooddrinkeurope.eu/ resource/data-trends- of-the-european-food-and-drink-industry-2020 / (accessed on 26 October 2021).

3. FAO. FAO Framework for the Urban Food Agenda; FAO: Rome, Italy, 2019. [CrossRef]

4. Saraiva, A.; Carrascosa, C.; Raheem, D.; Ramos, F.; Raposo, A. Natural Sweeteners: The Relevance of Food Naturalness for Consumers, Food Security Aspects, Sustainability and Health Impacts. Int. J. Environ. Res. Public Health 2020, 17, 6285. [CrossRef]

5. Ballesteros-Vivas, D.; Socas-Rodríguez, B.; Mendiola, J.A.; Ibáñez, E.; Cifuentes, A. Green Food Analysis: Current Trends and Perspectives. Curr. Opin. Green Sustain. Chem. 2021, 31, 100522. [CrossRef]

6. Agrawal, A.; Keçili, R.; Ghorbani-Bidkorbeh, F.; Hussain, C.M. Green Miniaturized Technologies in Analytical and Bioanalytical Chemistry. TrAC Trends Anal. Chem. 2021, 143, 116383. [CrossRef]

7. Dugheri, S.; Marrubini, G.; Mucci, N.; Cappelli, G.; Bonari, A.; Pompilio, I.; Trevisani, L.; Arcangeli, G. A Review of MicroSolid-Phase Extraction Techniques and Devices Applied in Sample Pretreatment Coupled with Chromatographic Analysis. Acta Chromatogr. 2021, 33, 99-111. [CrossRef]

8. Socas-Rodríguez, B.; Herrera-Herrera, A.V.; Asensio-Ramos, M.; Rodríguez-Delgado, M.Á. Recent Applications of Magnetic Nanoparticles in Food Analysis. Processes 2020, 8, 1140. [CrossRef]

9. Singh, A.; Ahmad, S.; Ahmad, A. Green Extraction Methods and Environmental Applications of Carotenoids-a Review. RSC Adv. 2015, 5, 62358-62393. [CrossRef]

10. Osorio-Tobón, J.F. Recent Advances and Comparisons of Conventional and Alternative Extraction Techniques of Phenolic Compounds. J. Food Sci. Technol. 2020, 57, 4299-4315. [CrossRef]

11. Hashemi, B.; Zohrabi, P.; Dehdashtian, S. Application of Green Solvents as Sorbent Modifiers in Sorptive-Based Extraction Techniques for Extraction of Environmental Pollutants. TrAC Trends Anal. Chem. 2018, 109, 50-61. [CrossRef]

12. Santana-Mayor, Á.; Rodríguez-Ramos, R.; Herrera-Herrera, A.V.; Socas-Rodríguez, B.; Rodríguez-Delgado, M.Á. Deep Eutectic Solvents. The New Generation of Green Solvents in Analytical Chemistry. TrAC Trends Anal. Chem. 2021, 134, 116108. [CrossRef]

13. Alipanahpour Dil, E.; Ghaedi, M.; Asfaram, A.; Tayebi, L.; Mehrabi, F. A Ferrofluidic Hydrophobic Deep Eutectic Solvent for the Extraction of Doxycycline from Urine, Blood Plasma and Milk Samples Prior to Its Determination by High-Performance Liquid Chromatography-Ultraviolet. J. Chromatogr. A 2020, 1613, 460695. [CrossRef]

14. Wang, D.-D.; Zhao, Y.; Ou Yang, M.-N.; Guo, H.-M.; Yang, Z.-H. Magnetic Polydopamine Modified with Deep Eutectic Solvent for the Magnetic Solid-Phase Extraction of Sulfonylurea Herbicides in Water Samples. J. Chromatogr. A 2019, 1601, 53-59. [CrossRef]

15. Jouyban, A.; Farajzadeh, M.A.; Mogaddam, M.R.A.; Nemati, M.; Nabil, A.A.A. Ferrofluid-Based Dispersive Liquid-Liquid Microextraction Using a Deep Eutectic Solvent as a Support: Applications in the Analysis of Polycyclic Aromatic Hydrocarbons in Grilled Meats. Anal. Methods 2020, 12, 1522-1531. [CrossRef]

16. Majidi, S.M.; Hadjmohammadi, M.R. Alcohol-Based Deep Eutectic Solvent as a Carrier of SiO2@Fe3O4 for the Development of Magnetic Dispersive Micro-Solid-Phase Extraction Method: Application for the Preconcentration and Determination of Morin in Apple and Grape Juices, Diluted and Acidic Ex. J. Sep. Sci. 2019, 42, 2842-2850. [CrossRef]

17. Babaee, S.; Daneshfar, A. Magnetic Deep Eutectic Solvent-Based Ultrasound-Assisted Liquid-Liquid Microextraction for Determination of Hexanal and Heptanal in Edible Oils Followed by Gas Chromatography-Flame Ionization Detection. Anal. Methods 2018, 10, 4162-4169. [CrossRef]

18. Piao, H.; Jiang, Y.; Qin, Z.; Ma, P.; Sun, Y.; Wang, X.; Song, D.; Fei, Q. Application of an In-Situ Formulated Magnetic Deep Eutectic Solvent for the Determination of Triazine Herbicides in Rice. Talanta 2021, 222, 121527. [CrossRef]

19. Li, X.; Dai, Y.; Row, K.H. Preparation of Two-Dimensional Magnetic Molecularly Imprinted Polymers Based on Boron Nitride and a Deep Eutectic Solvent for the Selective Recognition of Flavonoids. Analyst 2019, 144, 1777-1788. [CrossRef] 
20. Fu, N.; Li, L.; Liu, K.; Kim, C.K.; Li, J.; Zhu, T.; Li, J.; Tang, B. A Choline Chloride-Acrylic Acid Deep Eutectic Solvent Polymer Based on Fe3O4 Particles and MoS2 Sheets (Poly(ChCl-AA DES)@Fe3O4@MoS2) with Specific Recognition and Good Antibacterial Properties for $\beta$-lactoglobulin in Milk. Talanta 2019, 197, 567-577. [CrossRef]

21. Li, G.; Wang, X.; Row, K.H. Magnetic Solid-Phase Extraction with Fe3O4/Molecularly Imprinted Polymers Modified by Deep Eutectic Solvents and Ionic Liquids for the Rapid Purification of Alkaloid Isomers (Theobromine and Theophylline) from Green Tea. Molecules 2017, 22, 1061. [CrossRef]

22. Li, G.; Wang, X.; Row, K.H. Magnetic Molecularly Imprinted Polymers Based on Silica Modified by Deep Eutectic Solvents for the Rapid Simultaneous Magnetic-Based Solid-Phase Extraction of Salvia Miltiorrhiza Bunge, Glycine Max (Linn.) Merr and Green Tea. Electrophoresis 2018, 39, 1111-1118. [CrossRef]

23. Tan, L.; Li, Q.-Y.; Li, Y.-J.; Ma, R.-R.; He, J.-Y.; Jiang, Z.-F.; Yang, L.-L.; Wang, C.-Z.; Luo, L.; Zhang, Q.-H.; et al. Specific Adsorption and Determination of Aspartame in Soft Drinks with a Zein Magnetic Molecularly Imprinted Modified MGCE Sensor. RSC Adv. 2021, 11, 13486-13496. [CrossRef]

24. Fu, N.; Li, L.; Liu, X.; Fu, N.; Zhang, C.; Hu, L.; Li, D.; Tang, B.; Zhu, T. Specific Recognition of Polyphenols by Molecularly Imprinted Polymers Based on a Ternary Deep Eutectic Solvent. J. Chromatogr. A 2017, 1530, 23-34. [CrossRef] [PubMed]

25. Mirzajani, R.; Kardani, F.; Ramezani, Z. Fabrication of UMCM-1 Based Monolithic and Hollow Fiber-Metal-Organic Framework Deep Eutectic Solvents/Molecularly Imprinted Polymers and Their Use in Solid Phase Microextraction of Phthalate Esters in Yogurt, Water and Edible Oil by GC-FID. Food Chem. 2020, 314, 126179. [CrossRef] [PubMed]

26. Meng, J.; Wang, Y.; Zhou, Y.; Chen, J.; Wei, X.; Ni, R.; Liu, Z.; Xu, F. A Composite Consisting of a Deep Eutectic Solvent and Dispersed Magnetic Metal-Organic Framework (Type UiO-66-NH2) for Solid-Phase Extraction of RNA. Microchim. Acta 2020, 187, 58. [CrossRef] [PubMed]

27. Wei, X.; Wang, Y.; Chen, J.; Xu, F.; Liu, Z.; He, X.; Li, H.; Zhou, Y. Adsorption of Pharmaceuticals and Personal Care Products by Deep Eutectic Solvents-Regulated Magnetic Metal-Organic Framework Adsorbents: Performance and Mechanism. Chem. Eng. J. 2020, 392, 124808. [CrossRef]

28. Wei, X.; Wang, Y.; Chen, J.; Xu, P.; Xu, W.; Ni, R.; Meng, J.; Zhou, Y. Poly(Deep Eutectic Solvent)-Functionalized Magnetic Metal-Organic Framework Composites Coupled with Solid-Phase Extraction for the Selective Separation of Cationic Dyes. Anal. Chim. Acta 2019, 1056, 47-61. [CrossRef] [PubMed]

29. Song, X.; Zhang, R.; Xie, T.; Wang, S.; Cao, J. Deep Eutectic Solvent Micro-Functionalized Graphene Assisted Dispersive Micro Solid-Phase Extraction of Pyrethroid Insecticides in Natural Products. Front. Chem. 2019, 7, 594. [CrossRef]

30. Sun, L.; Deng, Q.; Zhu, T. Optimization of Heteroatom Doped Graphene Oxide by Deep Eutectic Solvents and the Application for Pipette-Tip Solid-Phase Extraction of Flavonoids. J. Sep. Sci. 2019, 42, 2371-2378. [CrossRef]

31. Karimi, M.; Dadfarnia, S.; Shabani, A.M.H.; Vafazadeh, R. Deep Eutectic Solvent Containing 2-(3-Hydroxy-1-Methylbut-2Enylideneamino)Pyridine-3-Ol Immobilized on Magnetic Graphene Oxide as a Selective Sorbent for Dispersive Micro-Solid Phase Extraction of Cadmium Ions. J. Iran. Chem. Soc. 2021, 18, 1311-1319. [CrossRef]

32. Hejazi Khah, M.; Jamshidi, P.; Shemirani, F. Applicability of an Eco-Friendly Deep Eutectic Solvent Loaded onto Magnetic Graphene Oxide to Preconcentrate Trace Amount of Indigotin Blue Dye. J. Mol. Liq. 2021, 342, 117346. [CrossRef]

33. Shirani, M.; Habibollahi, S.; Akbari, A. Centrifuge-Less Deep Eutectic Solvent Based Magnetic Nanofluid-Linked Air-Agitated Liquid-Liquid Microextraction Coupled with Electrothermal Atomic Absorption Spectrometry for Simultaneous Determination of Cadmium, Lead, Copper, and Arsenic in Food Sample. Food Chem. 2019, 281, 304-311. [CrossRef]

34. Shirani, M.; Akbari-adergani, B.; Jazi, M.B.; Akbari, A. Green Ultrasound Assisted Magnetic Nanofluid-Based Liquid Phase Microextraction Coupled with Gas Chromatography-Mass Spectrometry for Determination of Permethrin, Deltamethrin, and Cypermethrin Residues. Microchim. Acta 2019, 186, 674. [CrossRef] [PubMed]

35. Ye, L.-H.; Yang, J.; Wang, B.; Wang, Q.-Y.; Liu, F.; Du, L.-J.; Cao, J. A Novel Non-Covalent Functionalized Multi-Walled Carbon Nanotubes for the Microextraction of Bromophenols in Kelp and Seaweed. Microchem. J. 2019, 151, 104205. [CrossRef]

36. Yin, Q.; Wang, M.; Fang, D.; Zhu, Y.; Yang, L. Novel N,Cl-Doped Deep Eutectic Solvents-Based Carbon Dots as a Selective Fluorescent Probe for Determination of Morphine in Food. RSC Adv. 2021, 11, 16805-16813. [CrossRef]

37. Kasa, N.A.; Zaman, B.T.; Bakırdere, S. Ultra-Trace Cadmium Determination in Eucalyptus and Rosemary Tea Samples Using a Novel Method: Deep Eutectic Solvent Based Magnetic Nanofluid Liquid Phase Microextraction-Slotted Quartz Tube-Flame Atomic Absorption Spectrometry. J. Anal. At. Spectrom. 2020, 35, 2565-2572. [CrossRef]

38. Fan, C.; Wang, H.; Liu, Y.; Cao, X. New Deep Eutectic Solvent Based Superparamagnetic Nanofluid for Determination of Perfluoroalkyl Substances in Edible Oils. Talanta 2021, 228, 122214. [CrossRef]

39. Shishov, A.; Pochivalov, A.; Nugbienyo, L.; Andruch, V.; Bulatov, A. Deep Eutectic Solvents Are Not Only Effective Extractants. TrAC Trends Anal. Chem. 2020, 129, 115956. [CrossRef]

40. Cunha, S.C.; Fernandes, J.O. Extraction Techniques with Deep Eutectic Solvents. TrAC Trends Anal. Chem. 2018, 105, 225-239. [CrossRef] 